ITER Core Imaging X-Ray Spectrometer Conceptual Design and Performance Assessment - Phase 2

P. Beiersdorfer, J. Wen, J. Dunn, K. Morris

January 7, 2011 
This document was prepared as an account of work sponsored by an agency of the United States government. Neither the United States government nor Lawrence Livermore National Security, LLC, nor any of their employees makes any warranty, expressed or implied, or assumes any legal liability or responsibility for the accuracy, completeness, or usefulness of any information, apparatus, product, or process disclosed, or represents that its use would not infringe privately owned rights. Reference herein to any specific commercial product, process, or service by trade name, trademark, manufacturer, or otherwise does not necessarily constitute or imply its endorsement, recommendation, or favoring by the United States government or Lawrence Livermore National Security, LLC. The views and opinions of authors expressed herein do not necessarily state or reflect those of the United States government or Lawrence Livermore National Security, LLC, and shall not be used for advertising or product endorsement purposes.

This work performed under the auspices of the U.S. Department of Energy by Lawrence Livermore National Laboratory under Contract DE-AC52-07NA27344. 


\title{
ITER Core Imaging X-Ray Spectrometer Conceptual Design and Performance Assessment - Phase 2
}

\author{
Final Report on ORDER No. ICP008450-R \\ LLNL Expert Team \\ P. Beiersdorfer, J. Dunn, K. Morris, and J. Wen
}

December 31, 2010

\begin{abstract}
During Phase 2 of our study of the CIXS conceptual design we have tackled additional important issues that are unique to the ITER environment. These include the thermal control of the crystal and detector enclosures located in an environment with a $100^{\circ}-250^{\circ}$ $\mathrm{C}$ ambient temperature, tritium containment, and the range of crystal and detector movement based on the need for spectral adjustments and the desire to make measurements of colder plasmas. In addressing these issues we have selected a "Dewar"type enclosure for the crystals and detectors. Applying realistic view factors for radiant heat and making allowance for conduction we have made engineering studies of this enclosure and showed that the cooling requirements can be solved and the temperature can be kept sufficiently constant without compromising the specification parameters of the CIXS. We have chosen a minimum $3 \mathrm{~mm}$ combined thickness of the six beryllium windows needed in a Dewar-type enclosure and showed that a single window of $0.5 \mathrm{~mm}$ thickness satisfies tritium containment requirements. For measuring the temperature in cooler ITER plasmas, we have chosen to use the $\mathrm{K}$-shell lines of $\mathrm{Fe}^{24+}$. Iron is the preferred choice because its radiation can be analyzed with the identical CIXS settings used for analyzing the tungsten radiation, i.e., essentially no adjustments besides a simple crystal rotation need to be made. We have, however, included an $x y \theta$-drive motor arrangement in our design for fine adjustments and full rotation of the crystal mounts.
\end{abstract}




\section{INTRODUCTION}

The Core Imaging X-Ray Spectrometer (CIXS) is one of the diagnostic systems being provided by the United States as an in-kind contribution to the International Thermonuclear Experimental Reactor (ITER) collaboration. Specifically, the CIXS is one of several ITER diagnostic systems planned for core measurements of the ion and electron temperature profiles and of the toroidal and poloidal rotation velocity profiles, $\mathrm{T}_{\mathrm{i}}, \mathrm{T}_{\mathrm{e}}, \mathrm{v}_{\phi}$, and $\mathrm{v}_{\theta}$, respectively. The diagnostic is based on precision determinations of the Doppler broadening of the line shape and centroid line shift of the lines of highly ionized heavy impurities using a curved, spherically bent Bragg crystal spectral disperser and imager. This core system being provided by the US is complemented by two similar systems being developed by India - the edge imaging x-ray spectrometer and the x-ray crystal survey spectrometer. Data from both the core and edge spectrometers will need to be analyzed together to obtain spatially inverted, local measurements.

A preliminary study of this diagnostic for ITER by Barnsley et al. [1] recommended a configuration of CIXS views based on the utilization of solid state detectors, and on a preliminary neutronics assessment confirming the placement of these detectors near the rear of the equatorial port plug. This was followed by a design study in the US, done by LLNL in collaboration with PPPL [2,3]. This study reviewed previous work, developed a new conceptual design and CATIA model, and considered the use of intrinsic tungsten lines for the measurement, which offers some advantages.

An important aspect of this recent work has been an update of the integration of the diagnostic with cohabitants of the equatorial port plug. The CIXS diagnostic will be located in US port plug E9, along with the US Electron Cyclotron Emission diagnostic, the US Toroidal Interferometer Polarimeter diagnostic, and the EU Visible/IR Imaging System. The layout in the port plug has been modified from the previous study in order to accommodate the often time conflicting requirements of the various diagnostics. As a result, the CIXS layout has evolved from a layout with three toroidal and three radial (poloidal) imaging views, shown in Fig. 1(a) and summarized in the Phase 1 report [2] to a layout with two such views each. In a departure from the preliminary design study and in response to a preliminary neutronics analysis [1], the detector and crystal housing modules had been placed near the back wall in order to reduce the exposure to neutrons and to increase accessibility from the outside, cf. Figs. 1(a-c). This was accomplished in Phase 1 by selecting crystals so that the Bragg angles will be near $45^{\circ}$. While the Phase 2 was underway, it was suggested to move one of the two crystal/detector packages forward, as shown in Fig. 1(d), in order to increase coverage of the outer plasma regions, because the backside location provided coverage only to within $r / a>0.7$. The size of the active detector surface is also still in flux and driven by the available space. The spectrometer design of our Phase 1 study [2,3] has a demagnification of 5:1. This means a smaller detector height reduces the amount of plasma volume observed by the instrument, while a smaller width means less spectral coverage. As integration with the other diagnostics in port E9 progresses, further modifications are expected. 
(a)

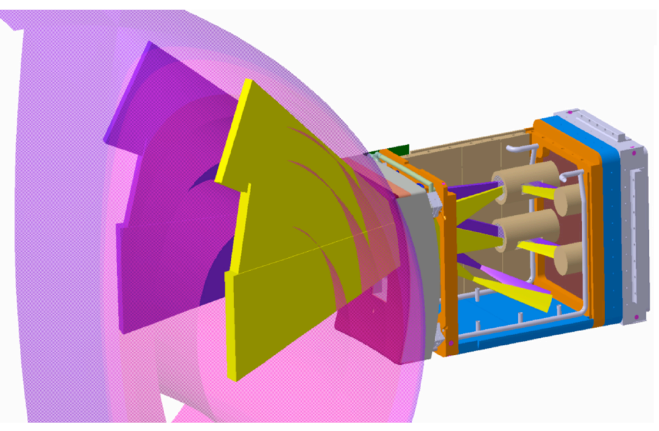

(b)

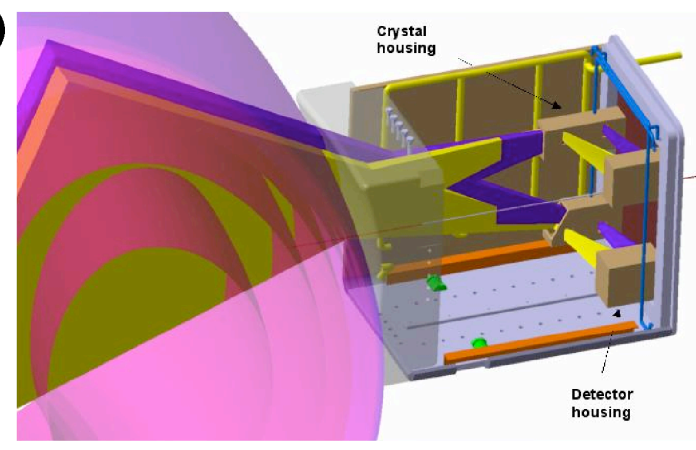

(c)

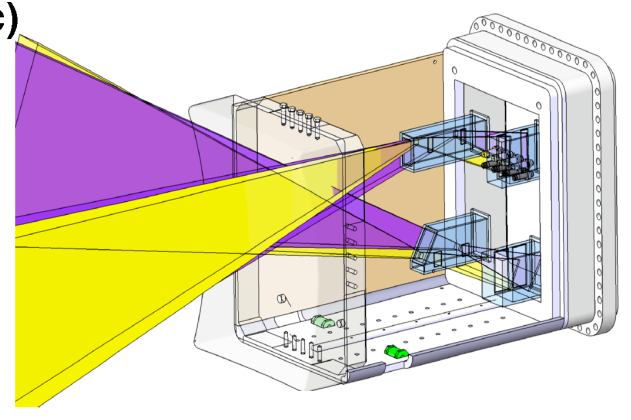

(d)

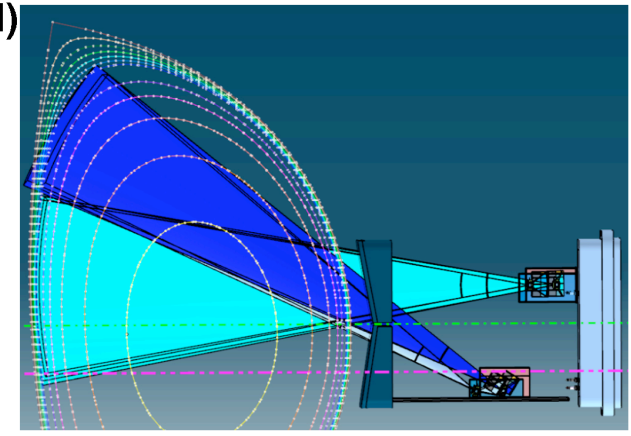

Figure 1 - Evolution of the design of the CIXS views and crystal/detector locations in US port plug EQ9.

\section{SCOPE OF PRESENT STUDY}

The scope of this study has involved physics studies, engineering layouts, and R\&D planning to refine the CIXS design for ITER, assess its operational capabilities, and optimize it with respect to physics demands and the hardware accessibility. Functional measurement specifications that relate to the CIXS design are shown in Tables 1 and 2. These specifications have been gathered from the ITER Diagnostic System Requirement Document (SRD - 55, IDM UID 28B39L) and the ITER Project Requirements Document (PR. IDM IUD 27ZRW8).

Another aspect of the present work has been to investigate engineering issues related to the modules that house the crystals and the detectors shown in Fig. 1. The crystals and the detectors must be thermally controlled. Presently envisioned detectors must be kept near room temperature, and the diffraction characteristics of the crystals are quite temperature sensitive. Part of this work has been to examine options for achieving this thermal control. 


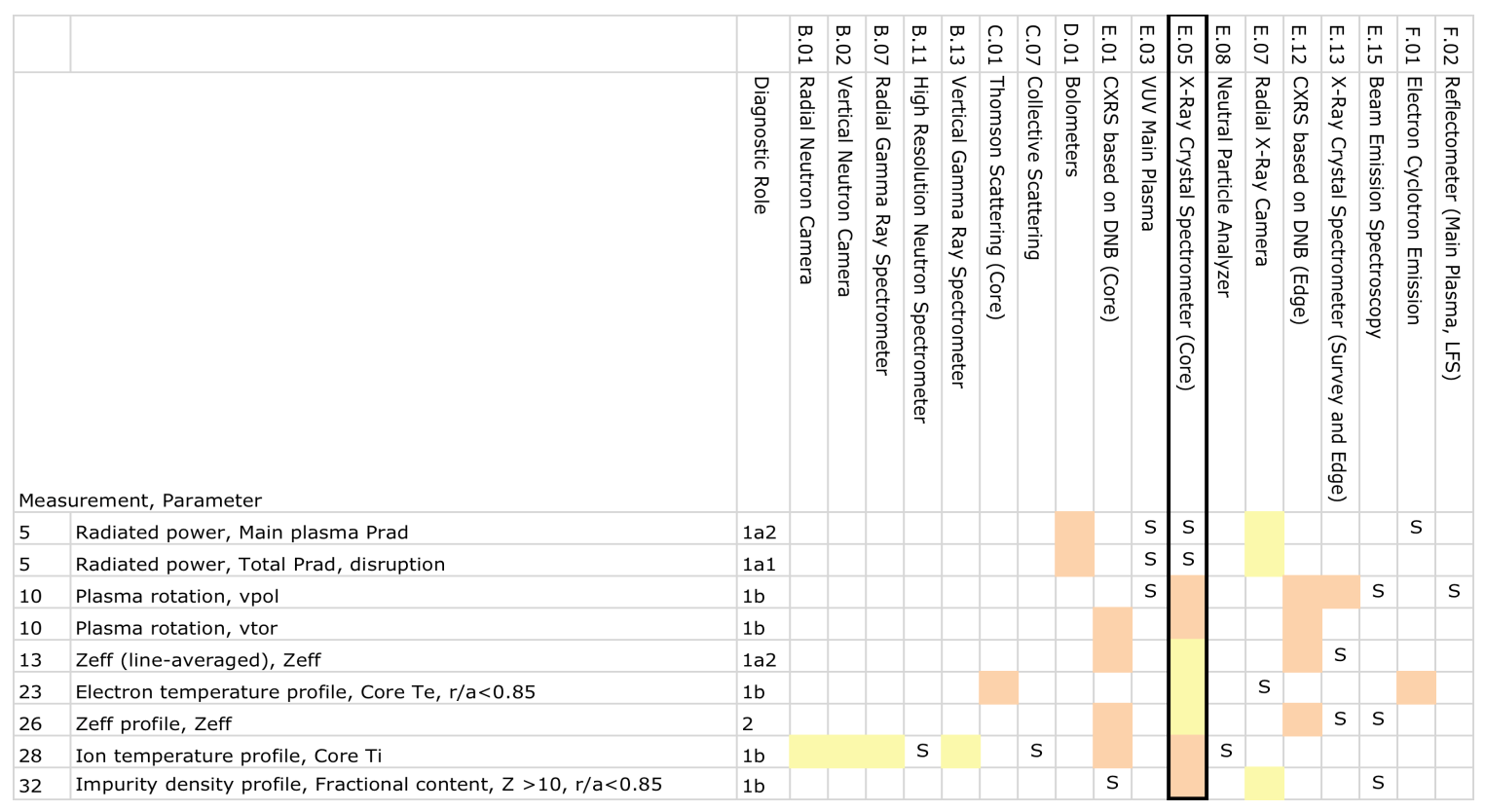

Table 1 - Contributions the CIXS may make to ITER Plasma Parameter Measurements.

One concept for cooling the detector and associated electronics uses He gas flowing inside a chamber near room temperature. Such a design, using a single-wall, rubbersealed chamber located in the ambient temperature environment of the Alcator test cell, is presently used on C-Mod $[4,5,6]$. The implementation of this concept on ITER will be more complicated as discussed in Section 3, since the outer walls of the chamber will need to be at $100^{\circ} \mathrm{C}$ for normal operation and will be heated to $240^{\circ} \mathrm{C}$ during ITER bakeout. Moreover, the presence of tritium will mean that all parts need to be vacuum compatible and leak tight. Part of this work has been to define tolerable gradients and to suggest concepts for achieving them. Fairly precise thermal control of the crystals is also needed, and the present report has quantified these requirements and recommends a design concept to satisfy them.

The present study has been performed by experts at LLNL in consultation with experts at PPPL, with R. Barnsley of the ITER Organization, with the port plug engineering group at PPPL (led by R. Feder), and with WBS leader D. Johnson. A summary of the specific tasks, which were led by the LLNL expert team, is given in Appendix A. The results from the LLNL study are presented in detail in Section 3. 


\begin{tabular}{|c|c|c|c|c|c|c|c|}
\hline Parameter & Measurement & Condition & Range & Time Res. & Spatial Res. & Rel. Accuracy & Abs. Accuracy \\
\hline Core Te & $\begin{array}{l}\text { 23. Electron } \\
\text { temperature } \\
\text { profile }\end{array}$ & $r / a<0.9$ & $0.5-40 \mathrm{keV}$ & $10 \mathrm{~ms}$ & $a / 30$ & TBD & - \\
\hline Core $\mathrm{Ti}$ & $\begin{array}{c}\text { 28. Ion } \\
\text { temperature } \\
\text { profile }\end{array}$ & $r / a<0.9$ & $0.5-40 \mathrm{keV}$ & $100 \mathrm{~ms}$ & $a / 30$ & 0.1 & - \\
\hline $\begin{array}{l}\text { Extrinsic ( } \mathrm{Ne} \text {, } \\
\mathrm{Ar}, \mathrm{Kr}) \text { influx }\end{array}$ & $\begin{array}{l}\text { 12. Impurity } \\
\text { species } \\
\text { monitoring }\end{array}$ & $r / a<0.9$ & - & - & - & 0.3 & $10 \%$ (rel.) \\
\hline $\begin{array}{c}\text { Extrinsic }(\mathrm{Ne} \text {, } \\
\mathrm{Ar}, \mathrm{Kr}) \text { rel. } \\
\text { conc. } \\
\end{array}$ & $\begin{array}{c}\text { 12. Impurity } \\
\text { species } \\
\text { monitoring }\end{array}$ & $r / a<0.9$ & $1 E-6-2 E-2$ & $10 \mathrm{~ms}$ & $a / 30$ & 0.3 & $10 \%$ (rel.) \\
\hline $\begin{array}{c}\begin{array}{c}\text { Fractional } \\
\text { content, } \mathrm{Z} \\
>10\end{array} \\
\end{array}$ & $\begin{array}{l}\text { 32. Impurity } \\
\text { density profile }\end{array}$ & $r / a<0.9$ & $1 e-6-0.3 \%$ & $10 \mathrm{~ms}$ & $a / 30$ & 0.3 & 0.1 \\
\hline VPOL & $\begin{array}{l}\text { 10. Plasma } \\
\text { rotation }\end{array}$ & (blank) & $\begin{array}{c}\begin{array}{c}\mathrm{vpol}=1-200 \\
\mathrm{~km} / \mathrm{s}\end{array} \\
\end{array}$ & $10 \mathrm{~ms}$ & $a / 30$ & 0.3 & - \\
\hline VTOR & $\begin{array}{l}\text { 10. Plasma } \\
\text { rotation }\end{array}$ & (blank) & $\begin{array}{c}\text { vTOR }= \\
1-200 \mathrm{~km} / \mathrm{s}\end{array}$ & $10 \mathrm{~ms}$ & $a / 30$ & 0.3 & - \\
\hline W rel. conc. & $\begin{array}{l}\text { 12. Impurity } \\
\text { species } \\
\text { monitoring }\end{array}$ & $r / a<0.9$ & $1 E-6-5 E-4$ & $10 \mathrm{~ms}$ & Profile & 0.3 & $10 \%$ (rel.) \\
\hline \multirow[t]{2}{*}{ Zeff } & \begin{tabular}{|c|}
$\begin{array}{c}\text { 13. Zeff (line- } \\
\text { averaged) }\end{array}$ \\
\end{tabular} & - & $1-5$ & $10 \mathrm{~ms}$ & Integral & 0.2 & - \\
\hline & 26. Zeff profile & Default & $1.0-5.0$ & $10 \mathrm{~ms}$ & $a / 30$ & TBD & - \\
\hline
\end{tabular}

Table 2 - Draft functional specifications for the ITER Core Imaging X-Ray Spectrometer Diagnostic (Extracted from ITER_D_26L94U v1.18).

\section{DETAILED ACCOMPLISHMENTS}

The ITER CIXS system utilizes the imaging properties of spherically bent crystals to obtain profiles of the ion temperature and bulk ion velocity by observing a large slice of the plasma. This type of instrument has first been suggested for implementation on NSTX [7] and has subsequently been successfully implemented on C-Mod using spherically bent quartz crystals and Pilatus-II two-dimensional detector arrays $[4,5,6]$. The conceptual layout of the ITER CIXS defined in Phase 1, however, differs in crucial ways from the Alcator spectrometer:

- The Alcator spectrometer utilizes argon as the trace impurity to track the ion temperature and bulk motion in the core. Argon cannot be used on ITER for core temperature measurements because argon will be fully stripped in the hot core and will no longer emit line radiation. As a result, we have designed the CIXS in Phase 1 to use tungsten as the tracer element for the CIXS system. In particular, the L-shell radiation of neonlike $\mathrm{W}^{64+}$ and neighboring charge states will be used as the 'working radiation' of the CIXS to measure core temperatures [2,3]. Even 
a W concentration as low as $10^{-6}$ is expected to provide enough signal to measure the core plasma parameters $[2,3]$.

- In Phase 1 we have chosen a Bragg angle close to $45^{\circ}$. At this angle, the sightline to the plasma and the light path between the crystal and the detector are at $90^{\circ}$ to each other and form an "L". This geometry allows us to fit both the crystals and detectors along the back wall of the port plug. Together with the neutron shielding inside the port plug, this minimizes the effect of the most intense neutron flux. Bragg angles smaller than $45^{\circ}$ allows us to locate the crystal further forward, while keeping the detector near the back wall (or even behind the back wall). A forwardly placed crystal can see plasma with larger tangency radii r/a, i.e., it can see more of the plasma edge. A Bragg angle of near $30^{\circ}$ had been chosen in our Phase 1 study [2] for the third view shown in Fig. 1(a), in order to obtain a view of the plasma near $\mathrm{r} / \mathrm{a}=0.9$. By contrast, the Alcator instrument utilizes a Bragg angle larger than $45^{\circ}$. Under this condition, the crystal sits farthest from the plasma and the detector is located in between. This is acceptable on Alcator, where neutron damage of the detector is not an issue. One should note that the advantages associated with a small Bragg angle (easier neutron shielding, extended view of the plasma edge) come at the price of lower resolving power. The resolving power scales with the tangent of the Bragg angle. To keep the resolving power acceptably high, the radius of curvature of the crystal must be adjusted within the constraint that the geometry must fit inside the port plug.

- The crystal material with the highest reflectivity and yet high intrinsic resolving power is germanium. As we showed in Phase 1, the CIXS instrumental throughput may be up to four times higher when using a germanium crystal rather than a quartz crystal for a given Bragg angle.

- The mechanical parts of the Alcator spectrometer are located at room temperature in the test cell and are enclosed by a single-wall chamber filled with helium. There is only one vacuum seal on a port on Alcator, which separates the tokamak vacuum from the spectrometer. On ITER all mechanical parts must fit into a port plug and a vacuum-tight enclosure must be used.

Details of the CIXS conceptual design has been documented in our Phase 1 report [2] and in a detailed scientific publication [3]. Additionally, we have described a concept to mitigate risk by using an x-ray calorimeter [8], and we have developed physics related to profile inversion $[9,10]$.

During Phase 2 of our study of the CIXS conceptual design we have tackled additional important issues that are unique to the ITER environment.

- The ambient temperature during ITER operation is expected to be $100^{\circ} \mathrm{C}$, and even higher $\left(250^{\circ} \mathrm{C}\right)$ during bakeout. The crystal and detector must operate at near room temperature, so that the cooling requirements are very high. Moreover, the temperature must be stable so as to not introduce thermal shifts that would 
mimic line shifts due to bulk motion. This adds an even higher level of constraint on the cooling system.

- The tritium use in ITER requires that the CIXS walls be designed to prevent unwanted contamination. All the while, the desired line radiation has to be able to get through the vacuum enclosure to the crystal and the detector. This puts constraints on the thickness of the beryllium windows and on the energy of the radiation that might be analyzed by the crystals.

- The temperatures in ITER will span a much wider range than in any other tokamak built so far. During high power operation the core temperature is expected to exceed $25 \mathrm{keV}$. However, during the initial years of operation highpower auxiliary heating systems will not be used, and the core plasma electron temperature will be below $10 \mathrm{keV}$. This is too low to produce $\mathrm{W}^{64+}$ ions, and the radiation from different ions may need to be used for measurement. Even in highpower discharges, the core temperature will be below $10 \mathrm{keV}$ during the first 100 seconds, when the plasma is heated only ohmically. This requires the identification of ions that can provide the appropriate working radiation for the CIXS given the constraints already imposed by the need to measure the core temperature during the high-power phase of the discharge.

- Remote adjustment of crystal and detector is necessary for a variety of reasons. The most extensive adjustments are expected from the desire to switch crystals in order to be able to observe different spectral lines.

In addressing these issues we have selected a "Dewar"-type enclosure for the crystals and detectors. Applying realistic view factors for radiant heat and making allowance for conduction we have made engineering studies of this enclosure and showed that the cooling requirements can be solved and the temperature can be kept sufficiently constant without compromising the specification parameters of the CIXS. We have chosen a 3 $\mathrm{mm}$ combined thickness of the six beryllium windows needed in a Dewar-type enclosure and showed that tritium permeation is not an issue. For measuring the temperature in cooler ITER plasmas, we have chosen to use the $\mathrm{K}$-shell lines of $\mathrm{Fe}^{24+}$. Iron is the preferred choice because its radiation can be analyzed with the identical CIXS settings used for analyzing the tungsten radiation, i.e., essentially no adjustments besides a simple crystal rotation need to be made. We have, however, included an xy $\theta$-drive motor arrangement in our design for fine adjustments. Moreover, the combined thickness of the beryllium windows is such that the iron radiation still is transmitted without the prohibitive loss experience by, for example, the K-shell radiation of argon.

The arguments that have led to these choices are given in detail below. 


\subsection{Be WINDOW THICKNESS RECOMMENDATION}

Beryllium is the material of choice because of its high strength and low-Z atomic number for vacuum windows that need to transmit $x$ rays. Our design in Phase 1 envisioned a single window with a thickness of $1 \mathrm{~mm}$. This thickness is sufficient to withstand atmospheric pressure even over a large surface area. A single window assumed that both the crystal and the detector shared the same enclosure. During CIXS integration into port plug E9, however, crystals and detectors were located in their own enclosures. This requires three beryllium windows - the first and second for the $\mathrm{x}$ rays to enter and exit the crystal housing, respectively, and the third to enter the detector enclosure. Thermal considerations discussed in Section 3.2 have further doubled the number of beryllium windows to a total of six.

If we keep the thickness of each window at $1 \mathrm{~mm}$, the combined thickness will be $6 \mathrm{~mm}$ of beryllium. The nominal transmissivity of this amount of Be at the $9.1 \mathrm{keV}$ energy of the $\mathrm{W}^{64+} \mathrm{x}$ rays is $45 \%$, as illustrated in Fig. 2. This is not a prohibitively small value, although it is half of what we assumed in our Phase 1 report $[2,3]$. Based on our calculations using the Flexible Atomic Code and an estimate of ITER plasma conditions, a Pilatus-II detector will still count about $2 \times 10^{6} \times$ rays per second per spatial resolution element even with such a thick amount of beryllium (given a $5 \mathrm{~cm}$ x $5 \mathrm{~cm}$ Ge crystal and a $25 \mathrm{keV}$ plasma with a mere $10^{-6}$ tungsten concentration).

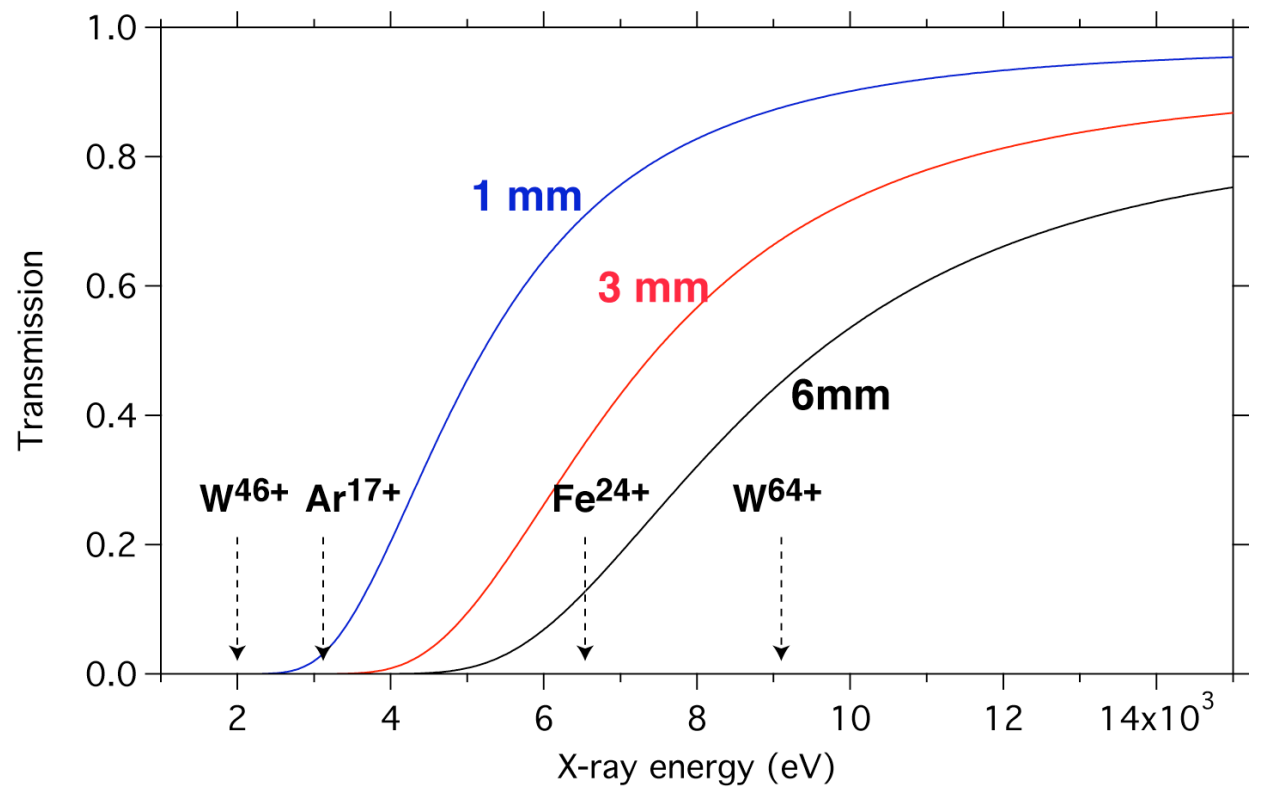

Figure 2 - Transmissivity of beryllium with three different thicknesses. The energy of x-ray lines from various ions is indicated. 
$\mathrm{X}$ rays with lower energy than those of tungsten will be more difficult to measure, if the beryllium window material is too thick. Lower energy $\mathrm{x}$ rays will be emitted from colder plasma regions and during discharge periods without auxiliary heating, and these will need to be useable by the CIXS. Lower charge states of tungsten, such as nickellike $\mathrm{W}^{46+}$, profusely emit M-shell radiation, which in principle could be analyzed to obtain the ion temperature in colder discharges. However, the tungsten M-shell radiation has an energy of about $2 \mathrm{keV}$ (3-4 transitions) to $2.8 \mathrm{keV}$ (3-5 transitions). Such energies are too low to be transmitted even through a $1 \mathrm{~mm}$ thick beryllium window, much less through material with a combined thickness of $6 \mathrm{~mm}$.

Argon has commonly been mentioned as a possible trace element for ITER. Like tungsten, argon has the advantage that it is likely to be indigenous to ITER plasmas. However, the argon K-shell radiation has an energy as high as $3.3 \mathrm{keV}$; its transmissivity is a mere $4 \%$ even for a $1 \mathrm{~mm}$ thick beryllium window and is vanishingly small for any higher thickness of material.

Considering the radiation of all candidate ions, the most reasonable choice is the K-shell radiation of heliumlike and hydrogenlike iron. The energy of the $\mathrm{K}$-shell $\mathrm{Fe}^{24+}$ lines is around $6.7 \mathrm{keV}$. The transmissivity of $6 \mathrm{~mm}$ Be at this energy is $14 \%$. This value is sufficiently high to allow use of iron radiation in the CIXS. Thinner Be windows, however, would improve the instrumental throughput, provide a greater margin of error, and increase the temporal response of the instrument.

The margin of error in beryllium window transmissivity is considerable when the overall transmissivity is small to begin with. The reason is that beryllium contains metallic impurities, all of which have a higher atomic number and thus a larger absorption than beryllium. The amount of metallic impurities varies by grade and is only partially characterized by the manufacturer.

Brush Wellman, which is the leading supplier of Be windows in the United States, offers three grades of beryllium: PS200 (standard purity), PF60 (high purity), and IF1 (ultrahigh purity). The high-Z impurities, even when present at very small concentrations, will considerably diminish the transmissivity of the window. In Fig. 3 we show the transmissivities of a $3 \mathrm{~mm}$ Be window we calculated for the standard and the ultrahigh purity grades. Of course, we were able to only include those impurities measured and listed by the manufacturer. The figure illustrates that there is a considerable reduction in the window transmissivity arising from the metallic impurities. The reduction is as high as $60 \%$ in the case of the standard grade. In the case of a combined $6 \mathrm{~mm}$ thick window the transmission of tungsten $\mathrm{W}^{64+}$ radiation, for example, drops to a mere $8 \%$, while the a value is $45 \%$ for pure Be! It is, thus, in the best interest of the CIXS performance to choose Be windows with the smallest allowable thickness.

Based on the Be yield strength of $43 \mathrm{ksi}$ we have calculated the thickness of a given window needed to withstand a pressure differential of one atmosphere. The required thickness depends strongly on the window size. There are openings of different sizes that 
need to be sealed with a beryllium window. The sizes depend on the assumptions made for the sizes of the crystals and of the detector arrays. In Phase 1 the crystal sizes were assumed to be $5 \mathrm{~cm} \mathrm{x} 5 \mathrm{~cm}$, and the detector arrays were assumed to be $40 \mathrm{~cm}$ tall and 3.2 $\mathrm{cm}$ wide. For our calculations, we assume the largest beryllium window dimension to be $40 \mathrm{~cm} \mathrm{x} 4 \mathrm{~cm}$.

(a)

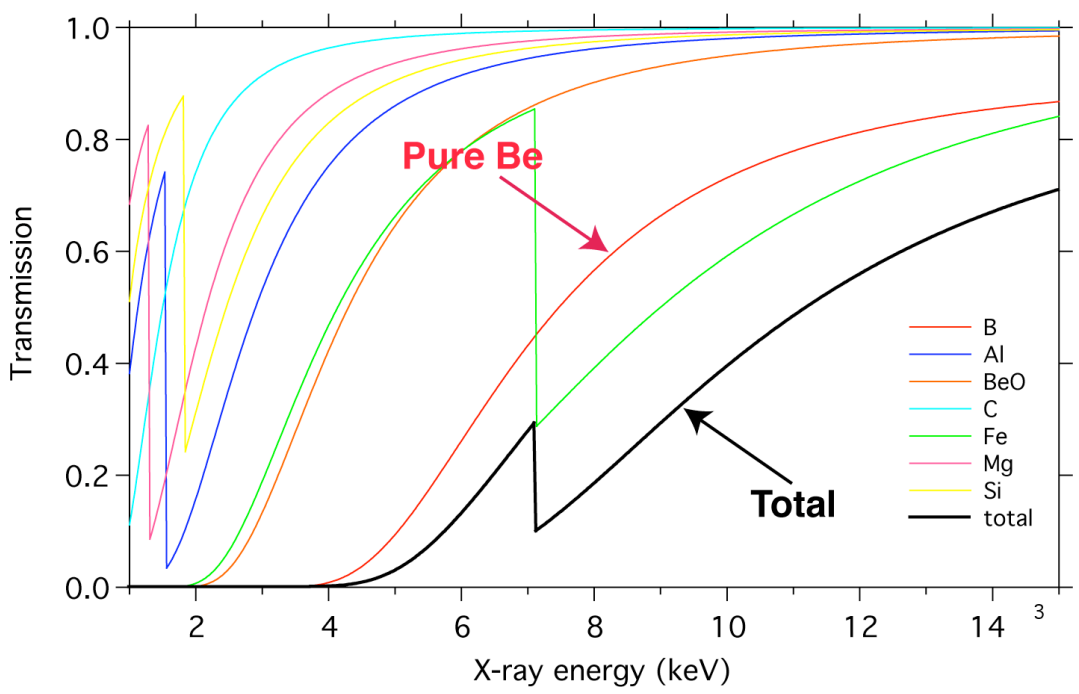

(b)

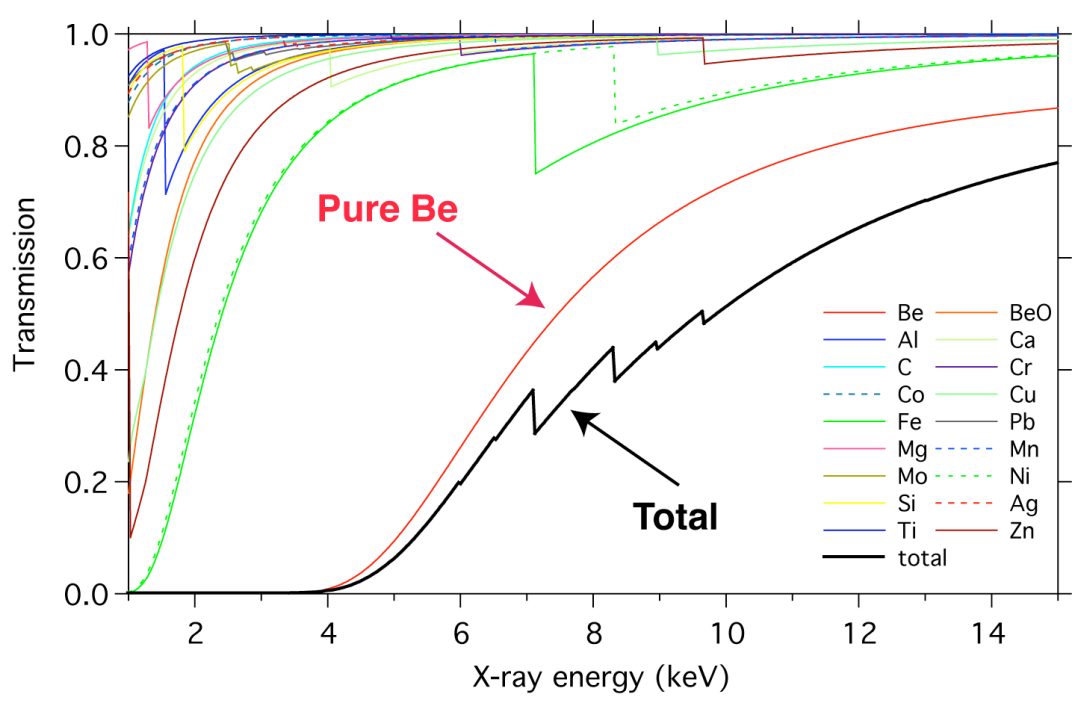

Figure 3 - Transmissivity of a $3 \mathrm{~mm}$ beryllium window including the effect of absorption from metallic impurities: (a) standard grade beryllium; (b) ultrahigh purity beryllium. 
A $40 \mathrm{~cm} \times 4 \mathrm{~cm}$ opening cannot be covered with a thin beryllium window without support structure. For our calculations we, therefore, divide the window into two by adding a supporting rib in the middle of the window so that the window effectively becomes two $40 \mathrm{~cm} \times 2 \mathrm{~cm}$ areas, as illustrated in Fig. 4. Doing this enables us to use a $0.5 \mathrm{~mm}$ thick beryllium window and still maintain a stress safety factor of 3.7. Similarly, a $5 \mathrm{~cm}$ x $5 \mathrm{~cm}$ window needs to be supported by a rib to yield a $5 \mathrm{~cm}$ by $2.5 \mathrm{~cm}$ area to be able to cover it with a $0.5 \mathrm{~mm}$ beryllium window.

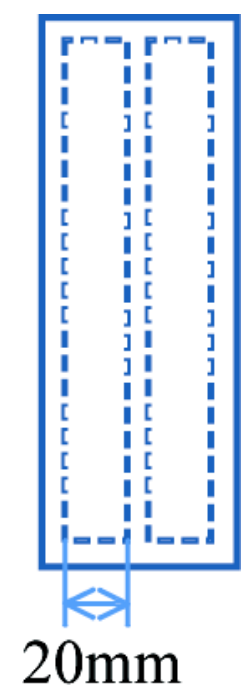

\section{Figure $4-40 \mathrm{~cm} \times 4 \mathrm{~cm}$ beryllium window supported by a single central rib to form effectively two $40 \mathrm{~cm} \times 2 \mathrm{~cm}$ areas.}

Using a single supporting rib on each window, thus, allows us to use a combined thickness of $3 \mathrm{~mm}$ of beryllium to cover the six openings. The transmissivity of the six windows is described by the curves in Fig. 3. Assuming the highest grade of beryllium, the transmissivity is $34 \%$ for $\mathrm{F}^{\mathrm{e} 24+}$ line radiation at $6.7 \mathrm{keV}$ and $46 \%$ for $\mathrm{W}^{64+}$ lines at 9.1 $\mathrm{keV}$.

The ribs will reduce the amount of either spectral or spatial coverage. We do not think that this will impact the CIXS performance considerably. For example, if the rib is placed such that blockage occurs in the spectral direction, the loss is minimal and will likely affect one of the satellite features, not the main line of interest. If by coincidence the shadow of the rib falls on the main line of interest, a simple adjustment by moving the crystal, as discussed in Section 3.4, will show the line again. Moreover, the rib material can be chosen so that not all of the radiation is absorbed. Adjustments for the signal loss due to the rib can then be made, if the rib transmissivity has been well characterized beforehand. 
A combined Be window thickness of $3 \mathrm{~mm}$ is thus our recommendation. This thickness can be decreased, if additional ribs or more sophisticated honeycomb support structures offered by Brush Wellman are considered. We note that large, circular Be windows (20 $\mathrm{cm}$ in diameter) have been successfully employed on NSTX and Alcator C-Mod. These are only $0.1 \mathrm{~mm}$ thick and utilize a honeycomb support.

\subsection{PREFERRED COOLING CONCEPT}

Adequate cooling of the CIXS components is crucial for their proper functioning. Cooling may be accomplished by flowing helium throughout the enclosures, by flowing water through the walls of the enclosure, or by electrical cooling (which, however, also requires an additional form of heat removal, such as a water line). These were the forms of cooling considered in this study. Other forms are also possible, such as conduction cooling from the outside, and could be incorporated at a later stage of the CIXS design.

In this Phase 2 study we focused on documenting the amount of heat flowing into the enclosures by conduction, the amount of heat entering by radiation, and the amount of heat generated internally, and whether it is possible to adequately remove the heat to keep the environment at the proper ambient temperature. In order to achieve a $1 \mathrm{~km} / \mathrm{sec}$ accuracy of CIXS measurements of the bulk ion flow velocities, it is necessary to maintain the crystal temperature within $\pm 0.1^{\circ} \mathrm{C}$. Thus is it important to find out whether we can achieve such temperature stability, and we performed a finite element analysis (FEA) to investigate the presence of temperature gradients that may compromise the functioning of the crystal.

We find that it is possible to adequately cool the enclosures by flowing helium gas through the enclosures. This sets a baseline scenario in which the crystal enclosure is kept at a temperature of $22 \pm 3^{\circ} \mathrm{C}$ during ITER bakeout and at a temperature of $22 \pm 0.1^{\circ}$ $\mathrm{C}$ during ITER operation. Similarly, the detector enclosure is kept at a temperature of 22 $\pm 3^{\circ} \mathrm{C}$ during ITER bakeout and at a temperature of $22 \pm 0.5^{\circ} \mathrm{C}$ during ITER operation. The baseline can be modified subsequently by adding water lines to the inner wall and Peltier coolers to the crystal and detector mounts, if desired to reduce the amount of gas

cooling. In fact, our calculations show that it is possible to achieve the same amount of cooling with water running though the inner wall and using a fan to equilibriate the temperature inside the enclosure. 


\subsubsection{Heat load}

\subsubsection{External heat loads}

The most crucial elements of the CIXS - crystals and detectors - by their very nature are exposed to radiation, and thus have a view (albeit mitigated by Be windows) to the (hot) outside. In order to calculate the heat flux impinging on these elements radiatively, we have calculated the viewing factor, i.e., the spatial acceptance angle, based on the two models (cf. Fig. 5) provided to us by PPPL. The view factors for the crystal to the plasma edge are $1.65 \times 10^{-5}$ and $1.82 \times 10^{-5}$ for the 'old' versus the 'new' model and thus differ only by $9 \%$.

(a)

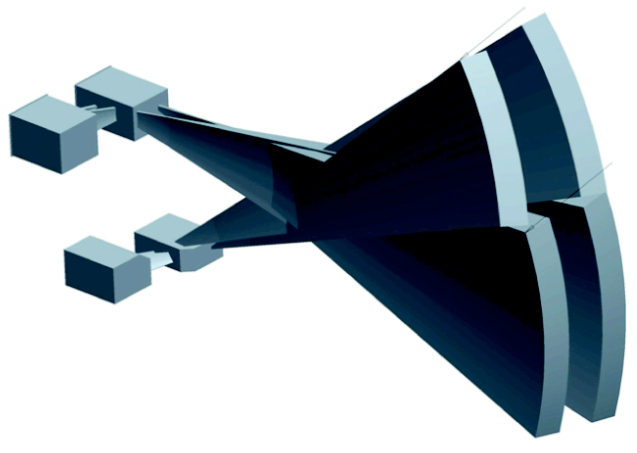

(b)

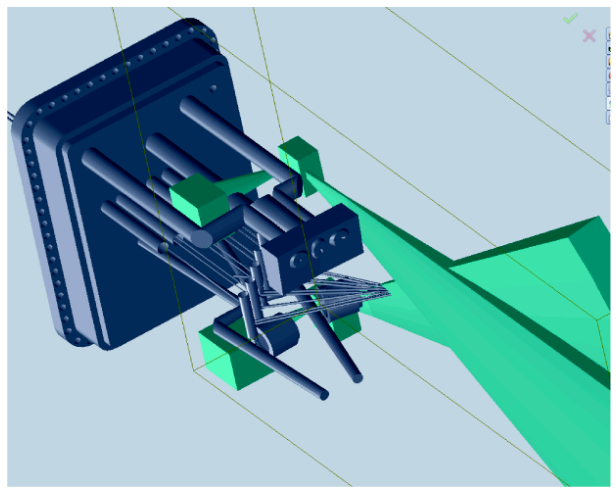

Figure 5 - CIXS models provided by PPPL: (a) 'old' model with two radial and two tangential views; (b) 'new' model with only two radial views; the tangential view was dropped at the time (Sept 2010) in favor of achieving integration with other instruments in port plug E9.

The radiative power entering through a single $5 \mathrm{~cm} \times 5 \mathrm{~cm}$ Be window viewing the plasma edge (set to a temperature of $600^{\circ} \mathrm{C}$ ) is less than $1 \mathrm{~W}$. This compares to the radiative power of almost $10 \mathrm{~W}$ entering the enclosure (inside temperature of $22^{\circ} \mathrm{C}$ ) from viewing the ambient environment at $250{ }^{\circ} \mathrm{C}$ during bakeout. Summing up the contributions from all windows we find a heat load of a little over $60 \mathrm{~W}$.

The radiative power load pales compared to the heat load associated with heat conduction through a single wall made of 304 stainless steel. A box with dimensions of $50 \mathrm{~cm} \times 30$ $\mathrm{cm} \times 76 \mathrm{~cm}$ and $1 \mathrm{~cm}$ thick walls has a heat load of $3.3 \mathrm{~kW}$ during the bakeout phase. 
The power load through a single wall is too high for adequate cooling. Consequently, we have adopted a Dewar-type enclosure, as illustrated in Fig. 6(a). Such an enclosure is not only double walled but each wall is coated with highly reflected material, typically silver. In addition, there must a be a vacuum of at least $10^{-3}$ torr between the two walls to keep the conduction below an acceptable value, as illustrated in Fig. 6(b). In the following we have adopted a thickness of $3.175 \mathrm{~mm}$ for each of the two stainless steel walls surrounding a $3.65 \mathrm{~mm}$ vacuum, as illustrated in Fig. 7 .

(a)

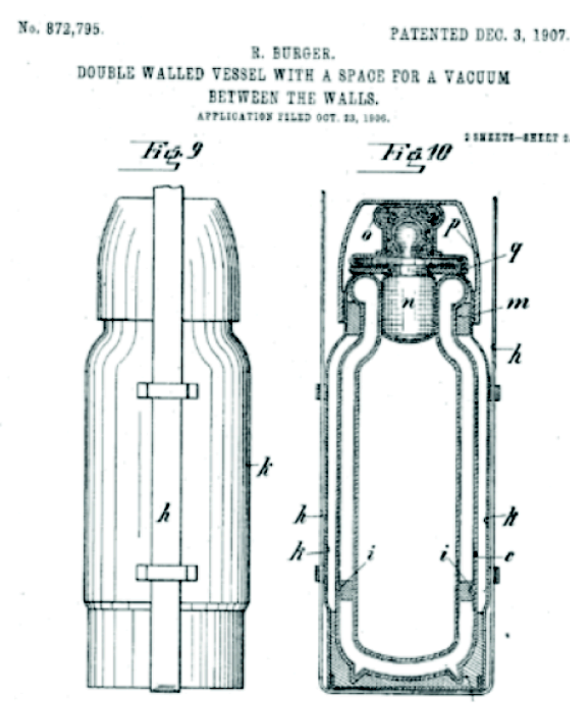

(b)

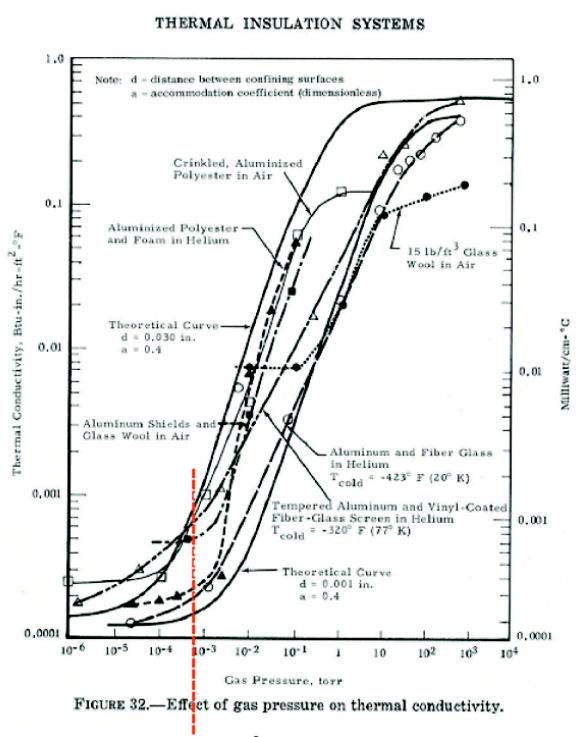

Needs to be Below $10^{-3}$ torr

Figure 6 - Dewar concept (a) and vacuum requirement (b) for proper functioning.

The heat load is greatly reduced when using the Dewar-type enclosure. We calculated 44 $\mathrm{W}$ entering a $22^{\circ} \mathrm{C}$ crystal enclosure during a $250^{\circ} \mathrm{C}$ bakeout, and about $7.8 \mathrm{~W}$ during ITER operations. The heat load of the detector enclosure is $50 \%$ higher because of it larger volume/surface area.

We note that this calculation assumes also a Dewar-type beryllium window arrangement of two highly reflective window separated by vacuum. Coating the each beryllium window with silver will not reduce the transmimissity significantly (a reduction below $4 \%$ ), if the thickness is on the order of 100 to $200 \AA$ per coat. Moreover, Brush Wellman is able to supply highly reflective $\mathrm{Be}$, which may need to be coated to achieve the same functionality as silver-coated Be. 

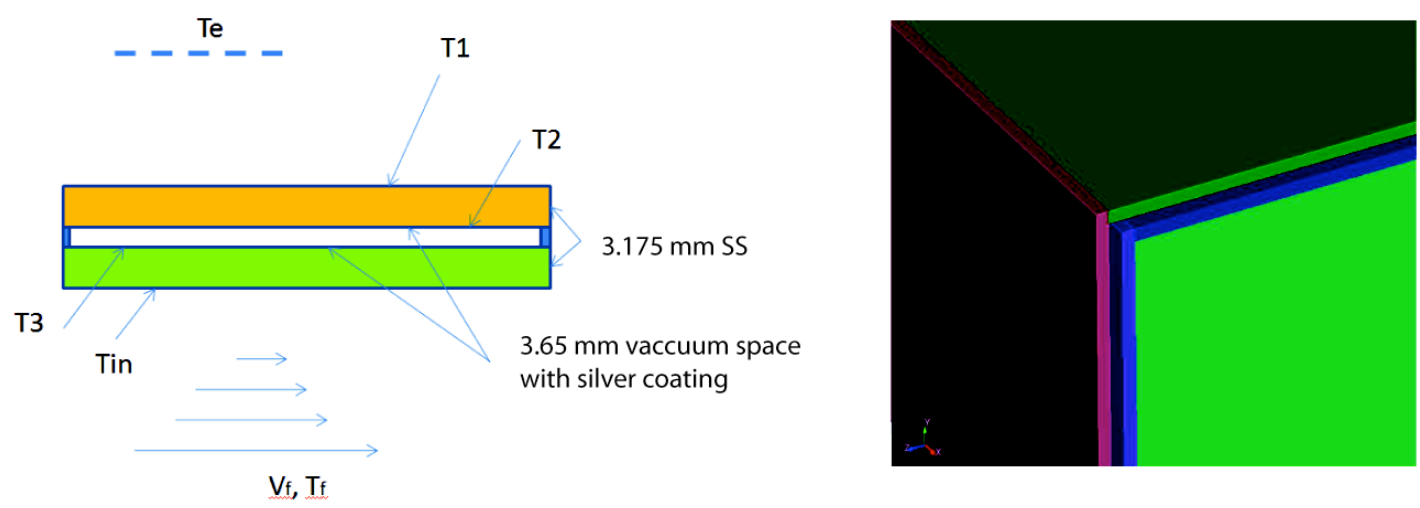

Figure 7 - Double wall concept used for crystal and dectector enclosures.

\subsubsection{Internal heat loads}

A conceptual arrangement of the crystal and detector mounts are shown in Fig. 8. Following our concept presented in Phase 1, we assume a crystal with dimensions of 5 $\mathrm{cm} \times 5 \mathrm{~cm}$, and a detector array $3.2 \mathrm{~cm}$ wide and about $40 \mathrm{~cm}$ tall (i.e., a stack of four Pilatus-II type detectors). Both crystal and detector array are mounted on two translation stages and one rotation stage.

(a)

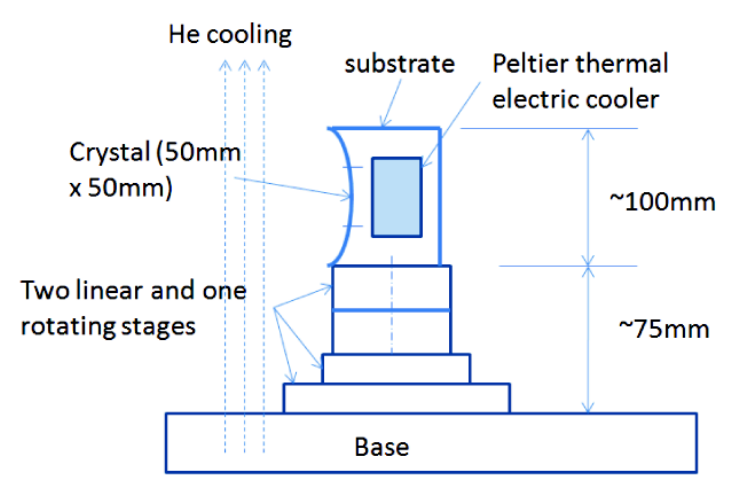

(b)

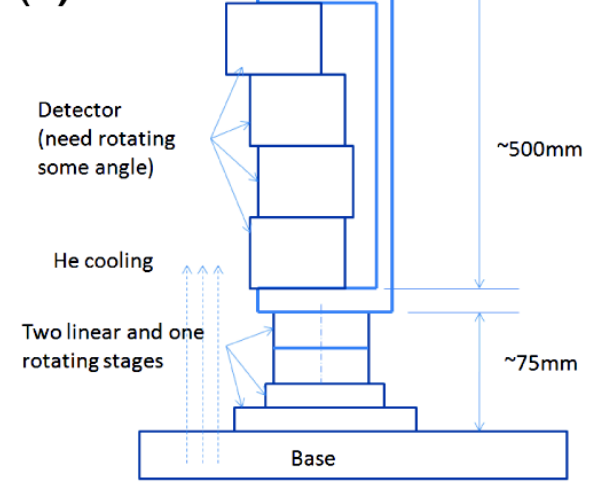

Figure 8 - Conceptual arrangement of (a) crystal and (b) detector array within their respective enclosures. Each sits on top of translational and rotational stages that provide $\mathrm{xy} \theta$ motion. 
For assessing the internal heat load we assume that the three stages give off $10 \mathrm{~W}$ of power. The motors may be off most of the time; however, power may be needed to clamped the stages in place. Each Pilatus-II detector consumes $15 \mathrm{~W}$ of power. Because there are two crystals in the crystal enclosure, the total internal power load is $20 \mathrm{~W}$ in the crystal enclosure. The total internal heat load in the detector enclosure is $140 \mathrm{~W}$.

\subsubsection{Cooling by Helium Flow}

Enclosure cooling by helium gas represents a baseline concept for thermal control, which can be modified later to include additional ways of removing heat and thus reducing the required helium flow rate. We envision helium gas to enter through the floor of the enclosure, as illustrated in Fig. 9. The helium is pumped out through the ceiling. The helium temperature is $20^{\circ} \mathrm{C}$ lower than the desired temperature in the enclosure.

(a)

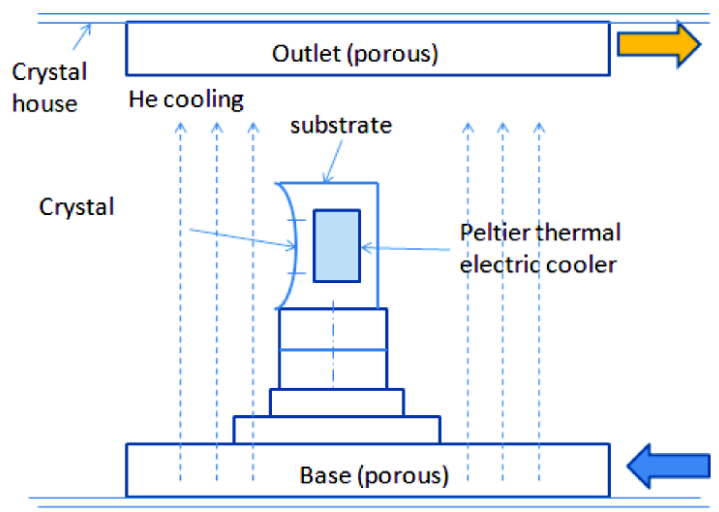

(b)

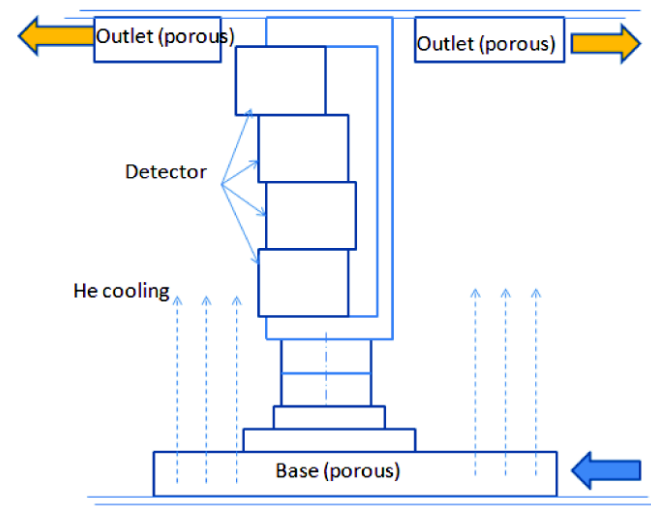

Figure 9 - Conceptual cooling arrangement of (a) crystal and (b) detector array housing. Helium gas enters the enclosure through the bottom wall and is removed though the top wall. An optional Peltier cooling element may be attached to the crystal mount or the detector electronics to provide additional cooling.

The calculated helium flow rate in the crystal enclosure needs to be $11.8 \mathrm{~m}^{3} /$ hour or 3.3 liter/sec to remove about $64 \mathrm{~W}$ of power during the bakeout phase. That rate is reduced to $5.8 \mathrm{~m}^{3} /$ hour or 1.6 liter $/ \mathrm{sec}$ to remove about $28 \mathrm{~W}$ of power during the operation phase. 
The calculated helium flow rate in the detector enclosure needs to be $38 \mathrm{~m}^{3} /$ hour to remove about $206 \mathrm{~W}$ of power during the bakeout phase, if the detectors are on. Most likely the detectors are off during that time, and the flow rate then needs to be only 12 $\mathrm{m}^{3} /$ hour. That rate is increased to $27 \mathrm{~m}^{3} /$ hour to remove about $152 \mathrm{~W}$ of power during the bakeout phase.

The flow rate can roughly be cut in half, if the temperature difference between the incoming gas and the enclosure temperature were doubled to $40^{\circ} \mathrm{C}$. In all of our calculations we made the assumption that the operating temperature inside of the enclosure is $22^{\circ} \mathrm{C}$. It is possible to raise this temperature to $30^{\circ} \mathrm{C}$, while reducing the helium gas temperature to $-10^{\circ} \mathrm{C}$ (or lower). However, in this case the crystals should be tested for being able to withstand thermal cycling.

\subsubsection{Temperature Gradients}

We have made FEA calculations using LSDYNA to investigate the temperature variations inside the crystal enclosure. The enclosure was modeled with a single window, and no specific details were assumed for the crystal holder and translation and rotation stages, except to model the heat input by the stages as coming from three individual knobs, as illustrated in Fig. 10 (a). Convergence of the calculations required to use a higher than desired convection coefficient of $3 \mathrm{Wm}^{-2} \mathrm{~K}^{-1}$. This means that the calculations should be repeated later for more realistic flow rates; however, the present calculations give a good indication that the desired temperature and a gradient control within $\pm 0.1^{\circ} \mathrm{C}$ can be achieved.

The calculations were carried out for multiple scenarios, including an outside temperature of $250^{\circ} \mathrm{C}$ (bakeout) and of $100^{\circ} \mathrm{C}$ (ITER operation). The results for the latter case are shown in Fig. 10. The temperature variation across the crystal is a mere $0.022^{\circ} \mathrm{C}$, which is well below what is necessary. Even for the bakeout case, the temperature variation across the crystal is no more than $0.068^{\circ} \mathrm{C}$.

Another way to assess how well the temperature can be tightly controlled is to assume that there is no feedback to the helium flow rate or helium temperature while the ambient ITER temperature changes by $\pm 10^{\circ} \mathrm{C}$. In other words, we calculated the change in the crystal temperature, as the ambient ITER changes from $90^{\circ}$ to $110^{\circ} \mathrm{C}$, while the cooling rate stays the same.

We find that the crystal temperature changes by less than $\pm 0.1^{\circ} \mathrm{C}$ unless the ambient temperature changes by more than about $\pm 3.5^{\circ} \mathrm{C}$. This is illustrated in Fig. 11. As before, the temperature variations across the crystal stay within $0.02^{\circ} \mathrm{C}$.

The results demonstrate the crystal temperature is stable even if the ambient temperature of ITER drifts and no active feedback is employed to adjust the helium coolant flow rate or temperature. 
(a)

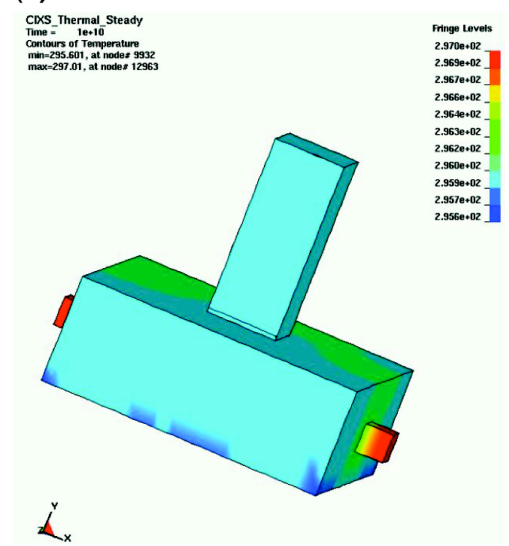

(b)

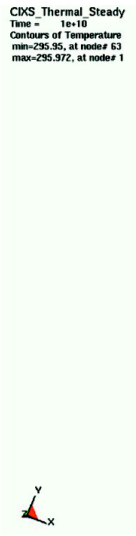

(c)

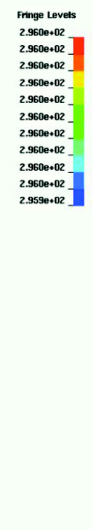

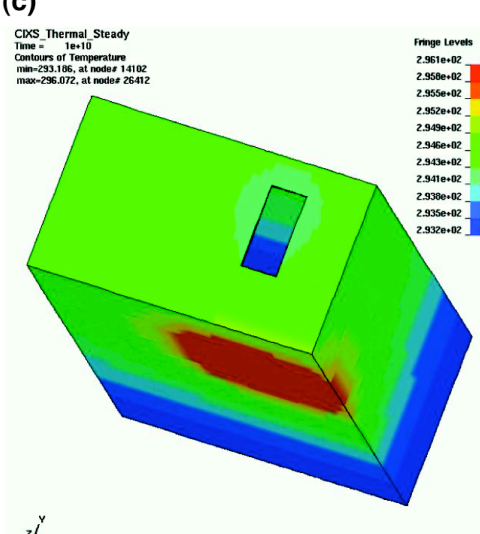

Figure 10 - LSDYNA simulation of the temperature variation inside the crystal housing. The temperature inside is set to $22^{\circ} \mathrm{C}$, while the ambient temperature is $100^{\circ} \mathrm{C}$. The crystal mount and translation stages are shown in (a); the front surface of the crystal holder is shown in (b); the inner wall of the Dewar-type enclosure is shown in (c). The outer wall of the Dewar-type enclosure is not shown.

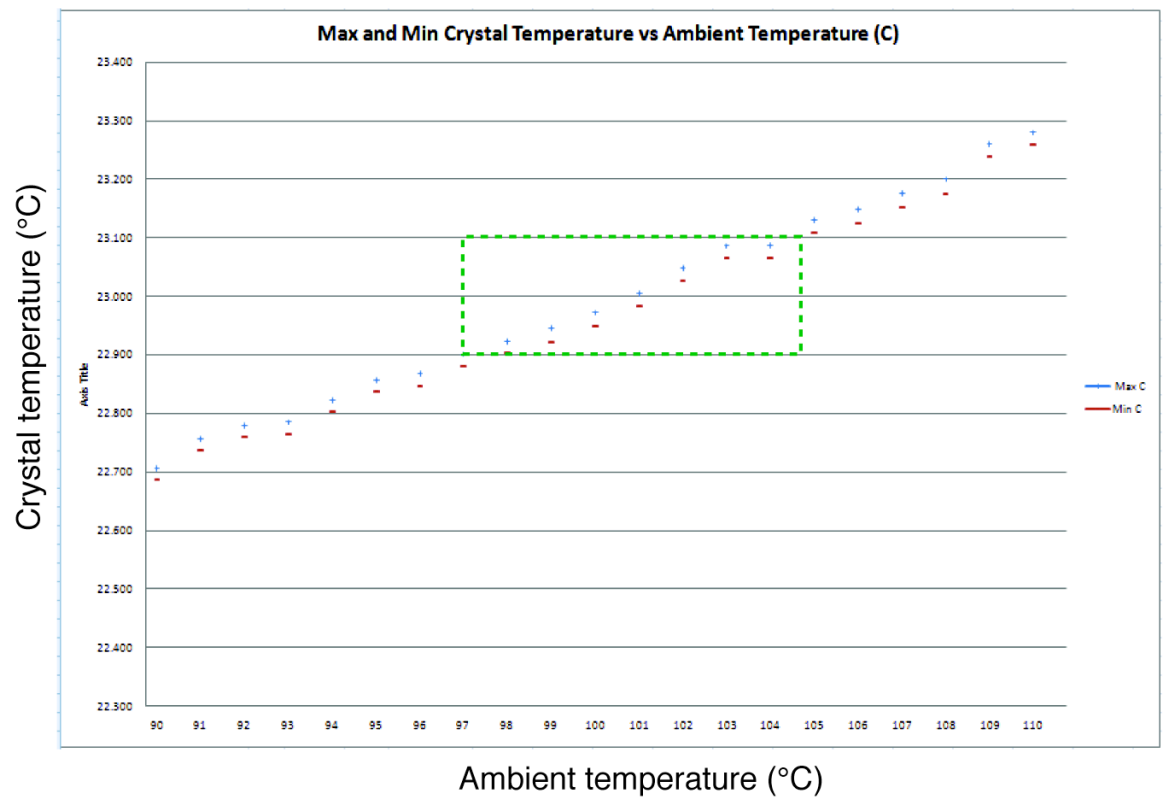

Figure 11 - Maximum and minimum temperature values of the crystal as the ambient temperature outside the enclosure varies. The helium flow rate and temperature is kept constant. 


\subsubsection{Cooling by Water Flow}

We have also considered cooling the enclosures by cooling the inner wall by water and equilibriating the temperature by means of a fan that stirs the helium atmosphere inside the enclosure. A schematic of this approach is shown in Fig. 12. The water pipes are embedded in the inner wall. Because the pipes are $12.7 \mathrm{~mm}$ in diameter, the inner wall thickness needs to be increased to $25 \mathrm{~mm}$.

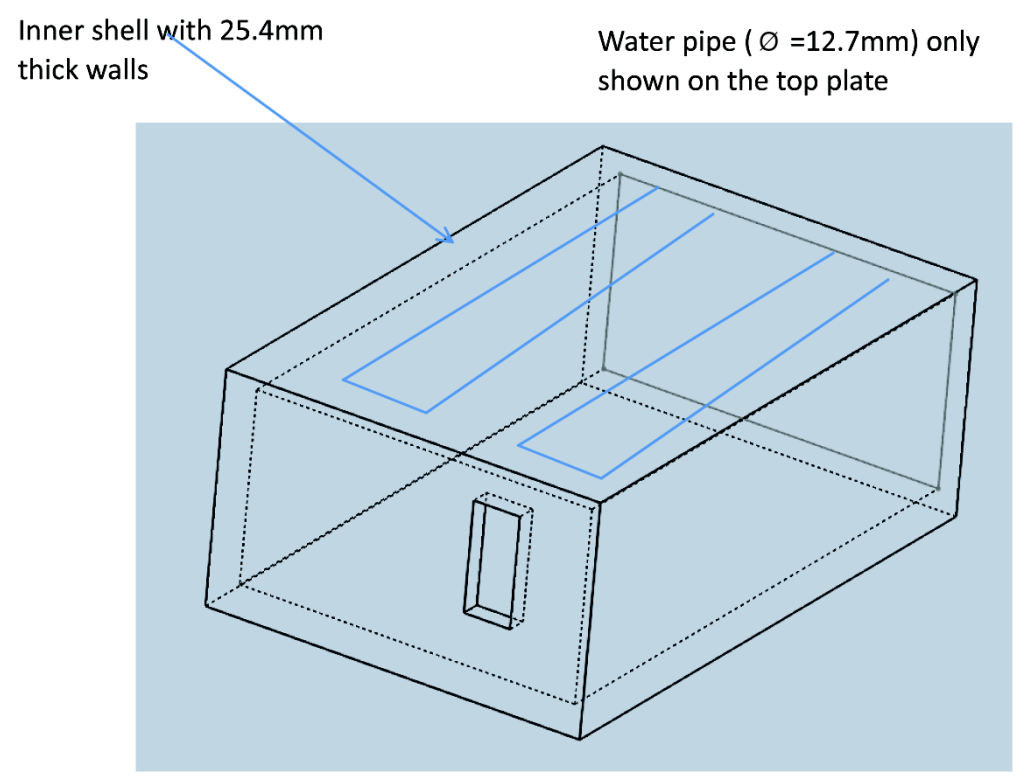

Figure 12 - Schematic of inner wall with embedded water pipes for cooling (blue). Only pipes on the top plate are shown.

We have calculated the amount of water flow to dissipate the heat and an equivalent convection coefficient that is required to force flow of the helium atmosphere inside the enclosure to maintain a uniform equilibrium temperature. The calculations show that this approach is viable, but helium convection coefficients are required that are similar in magnitude to those when helium flow is the sole coolant mechanism.

\subsubsection{Recommendation}

Our calculations and simulations show that the goal of maintaining the appropriate temperature within a tightly controlled range can be achieved, even if only a forced 
helium flow is employed. The helium in this case serves two roles: in the first role it is a coolant, and in the second role it is a medium that equilibriates the temperature.

We recommend the use of helium flow in the CIXS, because there is no substitute for its role in equilibriating the temperature among the items in a given enclosure. However, we also recommend employing water cooling of the inner wall to remove some of its heat load as well as Peltier coolers added to the detectors and motional stages to remove their waste heat. We note that the Pilatus-II manufacturer is already planning to supply detectors in the near future, which are water cooled. A Peltier cooler on the crystal mount may provide additional temperature control. Sensors placed on the crystal mount and other locations throughout the enclosure will provide input for adjusting the flow rate and coolant temperature.

\subsection{TRITIUM CONTAINMENT}

The pressure of tritium in ITER is about $1 \mathrm{mTorr}$ during a discharge, which lasts about $400 \mathrm{~s}$. The tritium level is negligible between discharges. There is concern that tritium may permeate the beryllium windows or the stainless steel walls of the CIXS and contaminate the crystals or detectors, which may need to be replaced during maintenance. As a result, we have made calculations of the amount of tritium permeating the CIXS vacuum enclosures.

Permeation is the penetration of a gas through a solid wall from a higher substance concentration to a lower one. It proceeds in three steps: (1) Sorption - gas is adsorbed at the surface of the solid; (2) Diffusion - the substance penetrates the solid through molecular gaps; it is temperature dependent and increases at higher temperatures. (3) Desorption - the substance leaves the solid as gas.

The amount of permeation is higher in steady state than in a pulsed situation like an ITER discharge. If tritium was constantly present outside the CIXS enclosures at a pressure of $1 \mathrm{~atm}$, then the amount that would permeate into the enclosure would be about $1.0 \times 10^{-8}$ mol during a $400 \mathrm{sec}$ period, or $3.5 \times 10^{-8} \mathrm{~g}$. However, for a pulsed situation, we calculated the total amount of tritium that permeates the beryllium windows in $86,400 \mathrm{sec}$ ( $24 \mathrm{hrs}$ ) to be $1.86 \times 10^{-14} \mathrm{~mol}\left(6.4 \times 10^{-14} \mathrm{~g}\right)$, in $40,000 \mathrm{sec}(11.1 \mathrm{hr})$ to be $1.35 \times 10^{-16}$ mol, in $4,000 \mathrm{sec}(1.1 \mathrm{hr})$ to be $1.48 \times 10^{-46} \mathrm{~mol}$, and during the $400 \mathrm{sec}$ of an ITER discharge to be vanishingly small.

The amount of tritium diffusion into the CIXS enclosures is thus negligible. Moreover, tritium entering the enclosure will be swept up in the helium flow and can be extracted by a cryogenic separator. 


\subsection{CRYSTAL AND DETECTOR SPATIAL ADJUSTMENTS}

We recommend the use of $x y \theta$ drives for adjusting the crystal and detector positions, as illustrated in Fig. 8. Adjustments of the crystal and detector positions are needed for several important reasons.

- The first is the need for fine adjustments after the system has been installed on ITER and mechanically and optically aligned. It is our experience that the need for fine adjustments becomes evident only once the system is operated as an X-ray system. One reason is that there typically are mechanical relaxations after the system has been installed caused by the pump down and or thermalization. The latter may be more severe on ITER because of the high bakeout temperatures of the port plug.

- The second reason is that the optical surfaces may not be aligned with the X-ray surfaces. In other words the crystal planes may not be parallel to the mechanical or optical surface of the crystal. This is usually a small effect (a few arc seconds to a few arc minutes), but it is unpredictable because crystal manufacturers do not warrant (or measure) the degree of coincidence of the optical and X-ray planes. Second, we are likely to need a support structure for the Be windows, as discussed in Section 3.1. It is important to be able to make a small shift of the crystal position so that obscuration by the Be window support does not affect the main diagnostic lines.

- Measurements of colder plasma may require observation of lower charge states than neonlike $\mathrm{W}^{64+}$. The core electron temperatures during the ohmic phase of an ITER discharge or the edge temperatures for $\mathrm{r} / \mathrm{a}>0.5$ during a high-power discharge are likely to be below $10 \mathrm{keV}$. At $10 \mathrm{keV}$ temperatures, the production of neonlike tungsten $\mathrm{W}^{64+}$ ions is not high and at even lower temperatures production is unlikely, as we have shown in our Phase 1 report [2,3]. Because of ion transport it is, however, likely that the radiation from $\mathrm{W}^{64+}$ ions will still be observed near the plasma edge, even if those ions are not produced at this location. Moreover, the design presented in Phase 1 recommends a spectral coverage that fills the full $3.2 \mathrm{~cm}$ width of a Pilatus-II detector and thus lines from lower charge states of tungsten, $\mathrm{W}^{63+}$ through $\mathrm{W}^{61+}$, will fall on the detector and can be used for measurement of colder plasmas. The spectral range can be extended further by being able to move the detector to the longer wavelength side of the spectrum (for this purpose, only the detector needs to be moved). A $25 \mathrm{~mm}$ translation stage would almost double the available spectral coverage. We note that the entrance windows of the detector enclosures must then be sized accordingly.

- Another very important reason for detector and crystal adjustments is the need to observe lines other than the high-temperature $\mathrm{W}^{64+}$ line and its neighbors during colder phases of ITER discharges. This has been discussed in Section 3.1, and we discuss this in additional detail below. 


\subsubsection{Recommended Choice for CIXS Measurements of Colder Plasmas}

The core electron temperatures of an ITER discharge do not rise above $10 \mathrm{keV}$ it is unlikely that sufficient amounts of neonlike tungsten $\mathrm{W}^{64+}$ ions will be produced for measurement, and ion transport from hotter to colder plasma regions will not be able to come to the rescue. In this case, the CIXS needs to utilize the radiation from ions with lower ionization stages. Because of the required thickness of the Be windows, we have already ruled out the use of radiation from lower charge states of tungsten as well a the $\mathrm{K}$-shell radiation of argon $(\mathrm{Z}=18)$. Possibilities are the $\mathrm{L}$-shell radiation of such heavy elements as xenon $(Z=54)$ and the $\mathrm{K}$-shell radiation from the transition metals. Although xenon is a noble gas and very easy to handle, it is unlikely that a heavy elements such as xenon will be added to ITER plasmas. The K-shell radiation of the lower- $Z$ transition metals, such as titanium $(Z=22)$, has no chance of penetrating the windows, and even the radiation of chromium $(Z=24)$ has little chance. This leaves us with such elements as manganese $(Z=25)$, iron $(Z=26)$, cobalt $(Z=27)$, nickel $(Z=28)$, or copper $(Z=29)$. Of these, iron is our recommended choice.

Iron will be in the heliumlike charge state for electron temperatures above $1 \mathrm{keV}$ and persist to about $10 \mathrm{keV}$. Hydrogenlike $\mathrm{Fe}^{25+}$ will persist even higher and its abundance peaks near $10 \mathrm{keV}$. This illustrated in Fig. 13.

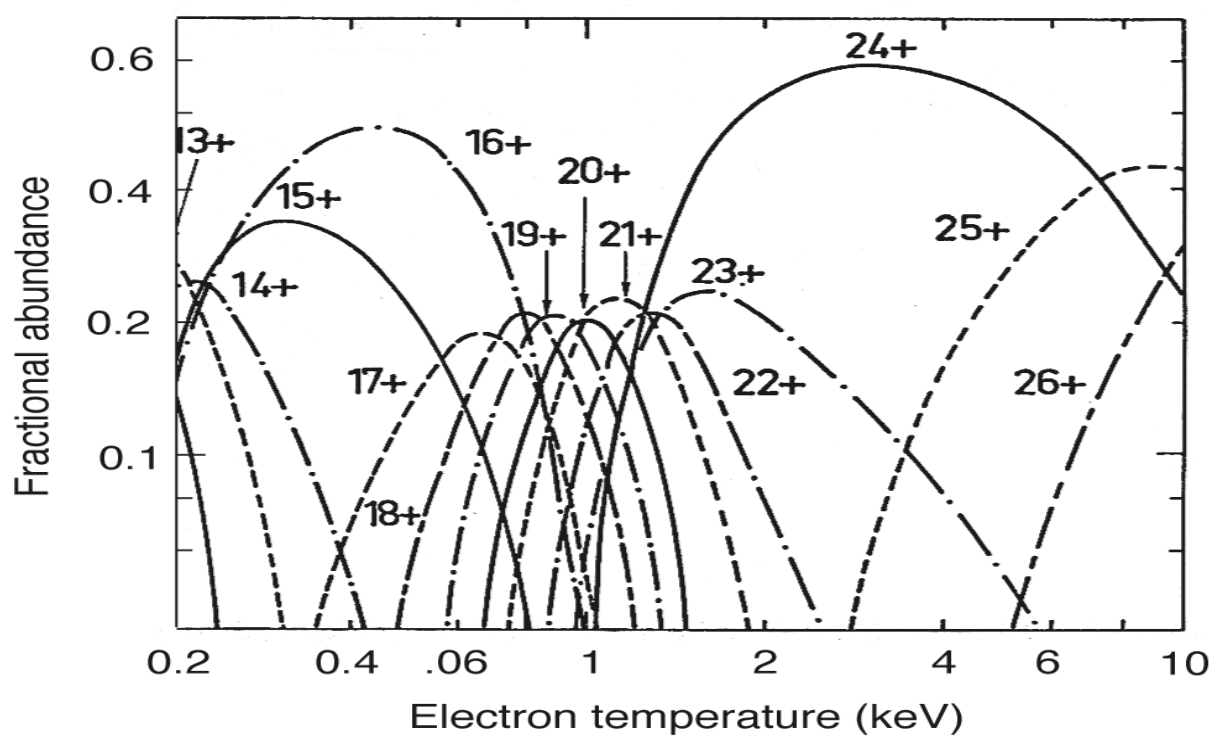

Figure 13 - Ionization fractions of iron as a function of electron temperature (from [11]). 
The emission from both heliumlike $\mathrm{Fe}^{24+}$ and hydrogenlike $\mathrm{Fe}^{25+}$ has been employed on many tokamaks as an ion temperature diagnostic and thus has been well studied. For example, the emission from $\mathrm{Fe}^{24+}$ has been used on TFTR to measure ion temperatures in excess of $24 \mathrm{keV}$, as illustrated in Fig. 14. Even for such high ion temperatures, however, the electron temperature in TFTR was low enough to be near the abundance peak of $\mathrm{Fe}^{24+}$.

(a)

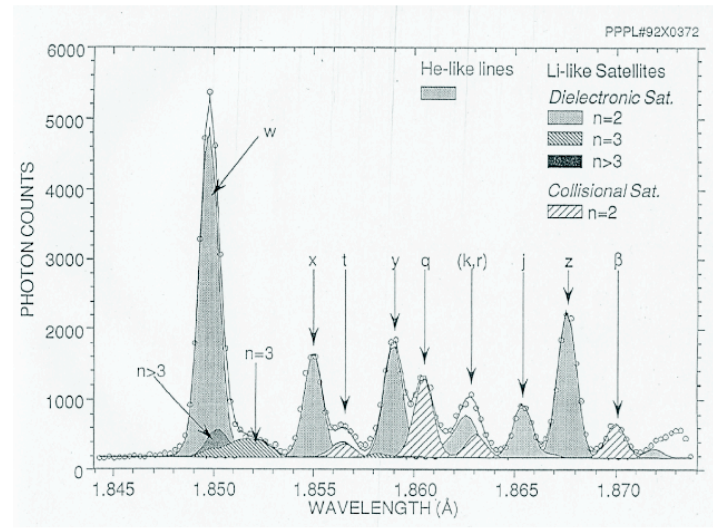

(b)

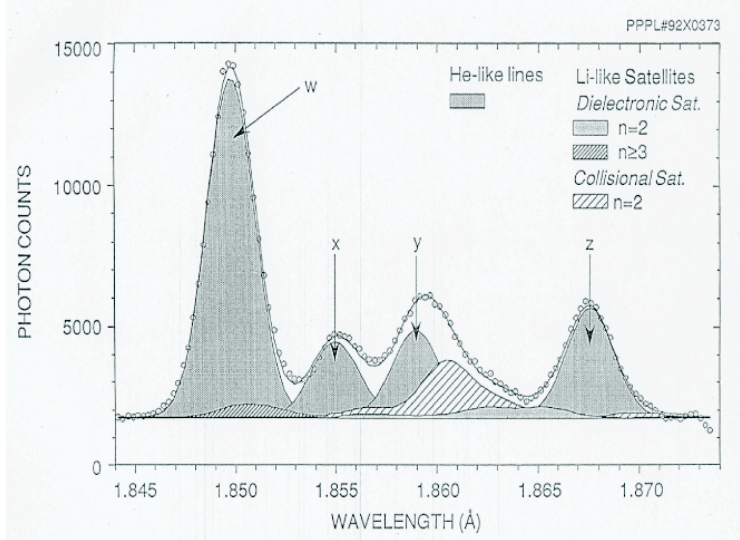

Figure 14 - Iron K-shell emission observed with the crystal spectrometer on TFTR: (a) $T_{i}=3 \mathrm{keV}$; (b) $T_{i} \geq 24 \mathrm{keV}$

(from [12]).

With the exception of tungsten, there are no high-Z elements expected in ITER plasmas with atomic number $Z>18$, i.e., no elements above argon. Iron will, thus, likely have to be introduced into ITER plasmas. This is not difficult to do by use of iron pentacarbonyl, $\mathrm{Fe}(\mathrm{CO})_{5}$, which is a liquid at room temperature and has a high vapor pressure so that it can be injected in gaseous form into ITER. This substance has been used successfully at the Livermore electron beam ion trap facility to produce iron plasmas for years. Its toxicity is rather low (decay in air produces iron oxide dust and carbon monoxide), so that handling and use can be done with rather simple ES\&H precautions. Iron penta-carbonyl should not be confused with ferrocene, $\mathrm{Fe}\left(\mathrm{C}_{5} \mathrm{H}_{5}\right)_{2}$, which was a proposed material for injection into TFTR and which is much more difficult to handle.

We envision that the $\mathrm{W}^{64+}$ line is used for measurement during the high (electron) temperature phase of ITER and the $\mathrm{Fe}^{24+}$ or $\mathrm{Fe}^{25+}$ lines are used during the lowtemperature phase. Because the iron lines require a different crystal than the tungsten lines, crystals need to be swapped when switching from iron to tungsten and vice versa. The crystals will be swapped using a simple $180^{\circ}$ rotation. For this, the crystals are mounted back to back on the crystal mount, as shown in Fig. 15. Because ITER discharges are very long, a typical measurement with the CIXS may start by observing 
iron for the first $100 \mathrm{sec}$ during which the plasma is heated ohmically, and proceed by flipping the crystal and observing tungsten during auxiliary heating for the next $200 \mathrm{sec}$. At the end of the discharge, iron may be observed again.

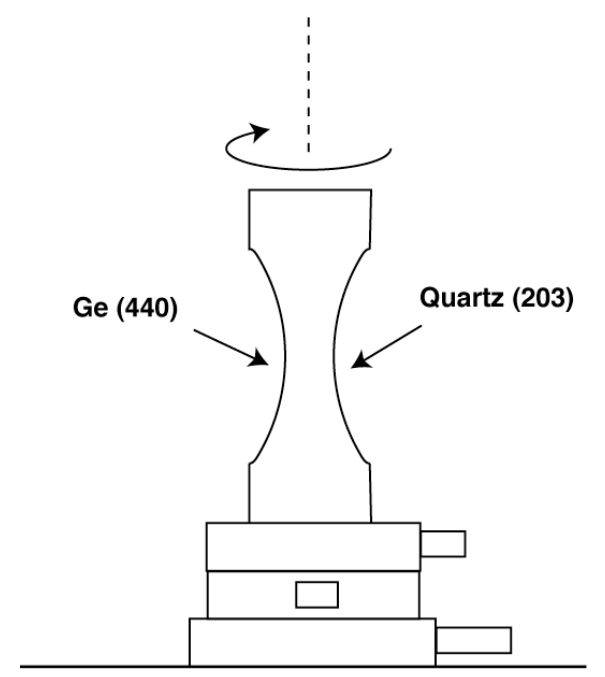

Figure 15 - Conceptual arrangement of the double crystal arrangement. By rotating the crystal mount by $180^{\circ}$ the Ge (440) crystal used for measuring tungsten can be swapped for a Quartz (203) crystal for measuring iron.

We have performed a search of applicable crystals that may have Bragg angles close to the Bragg angles envisioned for $\mathrm{W}^{64+}$. Two of the best choices are listed in Table 3 for both $\mathrm{Fe}^{24+}$ and $\mathrm{Fe}^{25+}$. As we found in our studies in Phase 1, germanium crystals outperform quartz crystals by offering a much higher reflectivity. Table 3 also lists the best choices for observing the $\mathrm{W}^{64+}$ line. We find that the Quartz (203) cut can measure the $\mathrm{Fe}^{24+}$ lines at essentially the same Bragg angle $\left(42.5^{\circ}\right)$ as the $\mathrm{Ge}(440)$ cut does for the $\mathrm{W}^{64+}$ line $\left(42.4^{\circ}\right)$. There is a nominal $0.1^{\circ}$ difference. This corresponds to a shift of 3.5 $\mathrm{mm}$ on the detector. (A difference of $1^{\circ}$ corresponds to a crystal or detector shift of 35 $\mathrm{mm}$.) Such a small change in position on the detector can be accommodated even with any translation of either crystal or detector. The combination of a Quartz (203) crystal for measuring the $\mathrm{Fe}^{24+}$ lines and a $\mathrm{Ge}(440)$ crystal for measuring the $\mathrm{W}^{64+}$ line is thus our first choice.

Measurement of the $\mathrm{Fe}^{25+}$ lines can also be accommodated, when using a $\mathrm{Ge}$ (331) crystal. However, there is a $0.8^{\circ}$ difference in the Bragg angle and a translation of crystal or detector by about $28 \mathrm{~mm}$ is required. 
Focusing on the $\mathrm{Fe}^{25+}$ Lyman lines has the advantage that measurements can be extended into higher plasma regions, although $\mathrm{Fe}^{24+}$ can also be observed at these higher temperatures, albeit that the radial abundance profile may become hollow toward the center of the plasma. But unlike $\mathrm{Fe}^{24+}$, hydrogenlike iron does not exist at the lower temperatures, i.e., below about $4 \mathrm{keV}$. Moreover, the signal provided by the Lyman lines of $\mathrm{Fe}^{25+}$ is considerably weaker than that provided by the resonance line " $w$ " of $\mathrm{Fe}^{24+}$. As we have done in Phase 1 for tungsten, we have used the Flexible Atomic Code to calculate the number of photons emitted per second per iron ion at the typical plasma conditions of $\mathrm{T}_{\mathrm{e}}=8 \mathrm{keV}$ and $\mathrm{n}_{\mathrm{e}}=10^{14} \mathrm{~cm}^{-3}$. As listed in Table 3, we find that 217 photons $/ \mathrm{sec} / \mathrm{Fe}^{24+}$ ion are emitted that form line "w", while only 85 photons $/ \mathrm{sec} / \mathrm{Fe}^{25+}$ ion are emitted that form line the Lyman-alpha 1 line. Taking all of this into consideration, we do not see a particular advantage in using the $\mathrm{Fe}^{25+}$ radiation.

\begin{tabular}{|c|c|c|c|}
\hline & $\mathrm{Fe}^{24+}$ & $\mathrm{Fe}^{25+}$ & $W^{64+}$ \\
\hline $\mathrm{T}_{\mathrm{e}}$ range & 1.5-8 keV & 6-12 keV & 10-35 keV \\
\hline$E_{x-\text { ray }}$ & $6.7 \mathrm{keV}$ & $7.0 \mathrm{keV}$ & $9.2 \mathrm{keV}$ \\
\hline Detector QE & $100 \%$ & $100 \%$ & $90 \%$ \\
\hline $3 \mathrm{~mm}$ Be window & $34 \%$ & $30 \%$ & $46 \%$ \\
\hline Quartz cut & $(20-23)$ & $(1-10-4)$ & $(5-2-3-1)$ \\
\hline Quartz $\theta_{\text {Bragg }}$ & 42.5 & 43.7 & 44.7 \\
\hline Quartz Reflect. & $16.0 \mu \mathrm{rad}$ & $10.2 \mu \mathrm{rad}$ & $4.7 \mu \mathrm{rad}$ \\
\hline Ge cut & (133) & (133) & $(440)$ \\
\hline Ge $\theta_{\text {Bragg }}$ & 45.6 & 43.2 & 42.4 \\
\hline Ge Reflect. & $33.3 \mu \mathrm{rad}$ & $30.5 \mu \mathrm{rad}$ & $18.8 \mu \mathrm{rad}$ \\
\hline $\begin{array}{l}\text { Emissivity } \\
@ 10^{14} \mathrm{~cm}^{-3}\end{array}$ & $\begin{array}{l}217 \mathrm{ph} / \mathrm{sec} / \text { ion } \\
\text { (@ } 8 \mathrm{keV})\end{array}$ & $\begin{array}{l}85 \mathrm{ph} / \mathrm{sec} / \text { ion } \\
\text { (@ } 8 \mathrm{keV})\end{array}$ & $\begin{array}{l}730 \mathrm{ph} / \mathrm{sec} / \text { ion } \\
\text { (@ } 25 \mathrm{keV})\end{array}$ \\
\hline
\end{tabular}

Table 3 - Comparison of the crystal choices, instrumental efficiencies, and atomic characteristics of the two iron lines with the main tungsten line. Note that the $\mathrm{Fe}^{24+}$ and $W^{64+}$ lines can be observed at essentially the same Bragg angle. 


\subsubsection{Summary}

Our discussion shows that mechanical adjustment of the detector and crystal positions will be needed. The crystal mount must be able to make a $180^{\circ}$ rotation in order to switch from one crystal to the other. Care must be taken that such a motion is not compromised by temperature sensor leads or pipes connected to a Peltier cooler. Adjustment of the detector and crystal xy positions range from a few $\mathrm{mm}$ to shift away from obscuration by a Be window support rib. Motion as much as $25 \mathrm{~mm}$ would allow accessing different spectral ranges, which may be important when trying to extend the measurement range to lines produced in plasma regions with higher or lower electron temperature.

It is difficult to predict the amount of adjustment that might be necessary to improve the initial optical alignment when installing the CIXS on ITER. Here we have to assume that the crystal planes have been well characterized beforehand and that other alignment errors during setup as well as shifts during pump down and thermalization are within the $25 \mathrm{~mm}$ motion of the xy drives.

We stress that motional stages should be equipped with position encoders to ensure reproducibility and to give the operators full knowledge of the position of all parts.

\section{FUTURE WORK TO DEFINE DESIGN CHOICES AND SUGGESTED RISK REDUCING R\&D}

During our Phase 1 work and again during our work on Phase 2 numerous issues have surfaced that need to be investigated in order to mitigate risks and firm up design choices. Many of these are not expected to significantly alter the conceptual design of the CIXS. They need to be considered, however, in the future when the CIXS is designed and built. One issue of major concern is the ability to perform a tomographic inversion of the data collected by the CIXS, as some views have disappeared and the total detector area has been cut from an initial array of five Pilatus-II detectors to only three. Investigation into the quality of the inversion as a function of views and plasma coverage under different ITER operating scenarios is outside our present scope of work. A related issue is the change in crystal and detector enclosure dimensions within the port plug integration

process. Some of the models use dimensions that may not be compatible with the need for cooling pipes, translation stages, electrical feeds, etc.

In the following we list some of the issues that pertain specifically to the design we have put forth in Phases 1 and 2. 


\section{New issues}

4.1 The current CIXS models used for integration appear to have crystal sizes that differ from the recommended value of $5 \mathrm{~cm} \mathrm{x} 5 \mathrm{~cm}$. We gather this because the enclosure entry windows determined by the spectrometer views in the models we received were smaller than the recommended crystal sizes. Similarly, the entry windows for the detector enclosures were smaller than the size of the detector array consisting of five Pilatus-II detectors.

The integration models presented at the US ITER Diagnostic Conceptual Design Review showed CIXS detector enclosures that could house three Pilatus-II detectors, and appeared too small to accommodate motional stages and walls thick enough to provide water and helium cooling. We recommend that the models include crystal and detector enclosures compatible with the cooling and motional requirements, lest further reduction in the imaging properties of the CIXS be required.

4.2 Integration considerations may allow a vacuum connection between the crystal and detector enclosures. This would eliminate the need for $4 \mathrm{Be}$ windows and thus the associated x-ray absorption. Such a design may also reduce the heat load by increasing the volume to surface ratio of the enclosure.

4.3 The possibility should be investigated to locate a combined crystal-detector enclosure outside the back plate of the port plug, or, if inside, make it reentrant for easier servicing and cooling.

4.5 The Be window thickness in the outer thermal wall could be reduced, if the "dewar" vacuum gap, i.e., the gap vacuum between the crystal or detector enclosure inner and outer walls, was coupled to the ITER vacuum system. As the ITER vacuum system underwent a pump or vent cycle, the enclosure gap vacuum would follow closely the ITER vacuum pressure. In that case, there would be no significant pressure differential. The outer Be window could be made very thin, as it would only need to withstand forces during venting and pump down cycles. The Dewar vacuum can then serve for tritium containment, even if the inner Be window is made very thin as well with the help of a support structure, as long as it is kept under ultra-high vacuum condition.

4.6 The composition and x-ray transmissivity of the Be windows will need to be characterized before installation on ITER, as even the highest purity Be window material contains unspecified amounts of metallic impurities. If the windows need to be coated for achieving high reflectivity, then the transmissivity of the coating will need to be characterized as well. Similarly, the quantum efficiency of the detector should be measured for the range of x-ray energies $(6.7-9.1 \mathrm{keV})$ relevant for the CIXS. 
4.7 Ray tracing calculations should be employed to investigate what the effects of the support ribs on the Be windows are on spectral response. It may be possible to locate the ribs in such a way that the spectral response is only diminished by not totally blocked.

4.8 The use of present-day Pilatus-II detectors is not optimal because of their relatively large pixel size $(172 \mu \mathrm{m} \times 172 \mu \mathrm{m})$ and its lack of a pulse-height discrimination feature. Detectors with smaller pixel sizes may allow the option to design a CIXS system with a larger demagnification than the value of 5:1 considered at present. In this case, the detector array size could be reduced without compromising plasma coverage. CIXS design options with increased demagnification should be considered, as such detectors may become available in time for use on ITER.

\section{Previous issues}

4.9 Germanium crystals offer multiple times higher efficiency than quartz. There is, however, little experience with spherically bent germanium crystals. Germanium is brittle and may relax by breaking during subsequent weeks or months after bending. We recommend an R\&D effort, for example using the EBIT radiation facility and a mock test setup at Livermore, to explore the usability of germanium crystals. Such an effort should also explore the effect of thermal cycling and the use of substrate material with similar thermal expansion coefficients.

4.10 The crystal reflectivities assumed here are based on calculated values available in the literature. These may not be accurate. Moreover, it is well known that they change when crystals are bent. Similarly, bending affects the achievable resolving power. We recommend an effort to measure the reflectivities and characterize the bent crystals (both quartz and germanium). This could be accomplished using EBIT and the crystal calibration facility operated by NSTEC, which is also located at Livermore.

4.11 The atomic data for L-shell tungsten measurements is essentially all theoretical and unchecked by experiment. We have produced many such theoretical data for our Phase 1 report. These data pertain to collisional satellite lines and the excitation rates of the neonlike lines. Additional theoretical data pertaining to dielectronic satellite lines have been produced by us in collaboration with atomic theorists at the University of Nevada, Reno. We recommend an experimental effort utilizing an EBIT to measure the positions and intensities of the collisional and dielectronic satellite lines. If improperly accounted for, such satellite lines can cause systematic errors in the temperature and rotation measurements, both of which rely on accurate determination of the line shape and position. 
4.12 Neutron bombardment of the detector and crystal may lead to irreversible damage. The rotating neutron source at Berkeley or other high-flux neutron sources, e.g. the National Ignition Facility at Livermore may be used to assess damage thresholds and failure modes.

4.13 Risk mitigation may also include the use of an x-ray calorimeter array on ITER. In a preliminary study, we determined that such an instrument required minimal port space (roughly a $2.5 \mathrm{~cm}$ vacuum tube), and the actual detector and electronics can be located outside the biological shield, i.e., tens of meters away from the plasma. The resolving power of such instruments is high enough (about $2 \mathrm{eV}$ ) so that the ion temperature can be determined from the line shape. While crystal spectrometers cover only a very small spectral band, $\mathrm{x}$-ray calorimeters would cover the entire spectral band between 2 and $10 \mathrm{keV}$. Thus, while it will be very hard to use crystal spectrometer data for $Z_{\text {eff }}, T_{e}$, and impurity concentration studies, the x-ray calorimeter data will provide such information with ease. Moreover, a radial ion temperature profile can be established from the broadening of the radiation from ions of different elements, each of which is located at different radial positions. A calorimeter detector can thus serve as a backup and will provide valuable additional data. We recommend that this technology be assessed and a potential diagnostic setup be modeled to augment the CIXS.

\section{REFERENCES}

[1] R. Barnsley, et al., "X-Ray Crystal Spectrometry”, EFDA 05-1350 D5.1

[2] P. Beiersdorfer, et al. "ITER Core Imaging X-Ray Spectrometer Conceptual Design and Performance Assessment", Final Report on Subcontract ICP008450-R, June, 2009 (avaialbel at http://www.pppl.gov/usiter-diagnostics).

[3] The ITER Core Imaging X-Ray Spectrometer

P. Beiersdorfer, J. Clementson, J. Dunn, M. F. Gu, K. Morris, Y. Podpaly, E. Wang, M. Bitter, R. Feder, K. W. Hill, D. Johnson, R. Barnsley

Journal of Physics B 43, 144008 (2010)

[4] Spatially Resolved Spectra from a new X-ray Imaging Crystal Spectrometer for Measurements of Ion and Electron Temperature Profiles

M. Bitter, K. W. Hill, B. Stratton, A. L. Roquemore, D. Mastrovito, S. G. Lee, J. G. Bak, M. K. Moon, U. W. Nam, G. Smith, J. E. Rice, P. Beiersdorfer, B. S. Fraenkel Review of Scientific Instruments 75, 3660-3665 (2004)

[5] A novel X-ray imaging crystal spectrometer for Doppler measurements of ion temperature and plasma rotation velocity profiles 
M. Bitter, K. W. Hill, S. Scott, A. Ince-Cushman, M. Reinke, J. E. Rice, P.

Beiersdorfer, M. F. Gu, S. G. Lee, Ch. Broennimann, E. F. Eikenberry, InProceedings of the IAEA International Workshop on Challenges in PlasmaSpectroscopy for Future Fusion Research Machines, editor Ram Prakash, Institute of Technology, India, ISBN 978-81-903047-8-8, 2008, pp. 121 - 125.

[6] A spatially resolving x-ray crystal spectrometer for measurement of iontemperature and rotation-velocity profiles on the Alcator C-Mod tokamak K. W. Hill, M. L. Bitter, S. D. Scott, A. Ince-Cushman, M. Reinke, J. E. Rice,P. Beiersdorfer, M. F. Gu, S. G. Lee, Ch. Broennimann, E. F. Eikenberry Review of Scientific Instruments 79, 10E320 (2008).

[7] A New Type of X-ray Imaging Crystal Spectrometer for NSTX M. Bitter, K. W. Hill, A. L. Roquemore, P. Beiersdorfer, S. M. Kahn, S. R. Elliott, B. Fraenkel

Review of Scientific Instruments $\underline{70}$, 292-295 (1999).

[8] The ITER Core Imaging X-Ray Spectrometer: X-Ray Calorimeter Performance P. Beiersdorfer, G. V. Brown, J. Clementson, J. Dunn, K. Morris, E. Wang, R. L. Kelley, C. A. Kilbourne, F. S. Porter, M. Bitter, R. Feder, K. W. Hill, D. Johnson, R. Barnsley

Review of Scientific Instruments 81, 10E323 (2010)

[9] Development of Spatially Resolving X-Ray Crystal Spectrometer (XCS) for Measurement of Ion-Temperature (Ti) and Rotation -Velocity (v) Profiles in ITER K. W. Hill, M. Bitter, L. F. Delgado Aparicio, D. Johnson, R. Feder, P. Beiersdorfer, J. Dunn, K. Morris, E. Wang, M. Reinke, Y. Podpaly, R. E. Rice, R. Barnsley, R. Mulhane, S. G. Lee

Review of Scientific Instruments 81, 10E322 (2010)

[10] Correcting the Johann Error for Spherically Bent X-Ray Imaging Crystal Spectrometers

E. Wang, P. Beiersdorfer, M. Gu, M. Bitter, L. Delgado-Aparicio, K. W. Hill, M. Reinke, J. E. Rice, and Y. Podpaly

Review of Scientific Instruments 81, 10E329 (2010)

[11] C. Breton, C. De Michelis, M. Finkenthal, and M. Mattioli, Fontenay-aux-Roses Laboratory Report No. EUR-CEA-FC-948 (1978).

[12] Measurements of the intercombination and forbidden lines from helium-like ions in Tokamaks and Electron Beam Ion Traps M. Bitter, K. W. Hill, S. von Goeler, W. Stodiek, P. Beiersdorfer, J. E. Rice, A. Ince-Cushman

Canadian Journal of Physics 86, 291-306 (2008) 


\section{Acknowledgments}

This work was performed under the auspices of the U. S. Department of Energy by Lawrence Livermore National Laboratory under Contract DE-AC52-07NA27344.

\section{APPENDIX}

\section{A. WORK DESCRIPTION}

Listed below are the specific work tasks to be performed by both PPPL and LLNL under the statement of work for USITER-15312-PD0003-R00. The specific work tasks led by the LLNL expert team are shown in boldface.

\section{A.1.Refine integration of the CIXS components into EQ9.}

A.1.1. Investigate increasing the toroidal component of the toroidal views., by exploring a reallocation of space among the diagnostic within the plug. (PPPL)

A.1.2. Investigate increasing the vertical range for both the radial and tangential upper fans. Assess the available range in terms of r/a referenced to the horizontal mid-plane. (PPPL)

A.1.3. Through parametric modeling in CATIA, refine the definition of the tapered, conical apertures for each of the four views as they extend through the BSM and the diagnostic shield modules. (PPPL).

A.1.4. Generic rear-mounted module (crystal and detector) issues

A.1.4.1. Refine module geometries and dimensions consistent with fully integrated port plug. (PPPL)

A.1.4.2. Develop "clear aperture" dimension requirements for Be windows (PPPL)

A.1.4.3. Develop Be window thickness recommendations. (LLNL lead)

A.1.4.4. Review existing techniques for cooling crystals, detectors and associated electronics including:

i) Cold-finger conduction cooling with cooled component in vacuum

ii) Flowing He gas cooling of components and chamber inner walls with external heat transfer from He gas

iii) He gas cooling of detectors with heat transfer between He gas fill and internal water-cooled walls.

iv) Other suggested cooling options.

Rough calculations to support this review should be included in report. Recommend preferred cooling concept. 

A.1.4.5. Develop a concept for thermal gradient control at vacuum boundaries at Be window, and at demountable rear flange seals, with thermal modeling analysis to validate concepts (LLNL)
A.1.4.6. Recommend tritium containment strategy compliant with ITER requirements. (LLNL)

A.1.5. Refine requirements for crystal environment and mounts
A.1.5.1. Assess needs for crystal spatial adjustments, including \# degrees of freedom and adjustment range, precision, and stability for each. (LLNL lead)

A.1.5.2. Document thermal control requirement for crystals (PPPL lead)

A.1.6. Refine requirements for detector environment and mounts

A.1.6.1. Assess needs for detector spatial adjustments, including \# degrees of freedom and adjustment range, precision, and stability for each. (LLNL lead)
A.1.6.2. Document thermal control requirements for detectors (PPPL lead)

A.1.7. Assessment of performance and comparison with functional specifications listed in Table 1.

A.1.7.1. Develop numerical simulation tools for predicting ITER background and signal components. (PPPL lead)
A.1.7.2. Develop suitable spatial inversion software to permit a local determination of $T_{i}$ and rotation profiles and associated uncertainties with realistic background assumptions. (PPPL lead)

A.1.7.3. Using the geometry resulting from 4.1.1, and standard ITER plasma scenarios, compute measured $\mathrm{T}_{\mathrm{i}}$ and rotation profiles and corresponding uncertainties. (PPPL)

A.1.7.4. Using the results of 4.1.7.3, review the values of Table 1, adding new rows and qualification notes as needed to define predicted CIXS performance. (PPPL)

A.2.List areas of high risk and recommend R\&D tasks needed to reduce risks and define design choices. (LLNL)

A.3.Jointly with the PPPL Port Engineering Team, present the results of this design effort at a Conceptual Design Review, with participation from the ITER Organization (IO) Diagnostics Division (see references 1.3.4, 1.3.5 and 1.3.6). Presentation should include:

A.3.1. Description of system layout, justifying choices for the proposed geometry.

A.3.2. Description of expected system performance, relative to the entries in Table 1.

A.3.3. Description of the diagnostic cassette, which houses the CXIS components and the mounting concepts for these components. 
A.3.4. Description of interfaces with the first-wall/blanket shield on EQ9 and with the back plate on EQ9.

A.4.Present description of conceptual design in a written report and at a workshop, topical meeting, conference, or seminar to be determined by the performing institution based on relevant technical audience and chronology and prior approval by the PPPL Technical Representative. (LLNL) 